\title{
Article \\ Performance Evaluation of an Adsorption Heat Pump System Using MSC-30/R1234yf Pair with the Impact of Thermal Masses
}

\author{
Sangwon Seo ${ }^{1, *}$, František Mikšík ${ }^{1,2}$, Yuta Maeshiro ${ }^{1}$, Kyaw Thu ${ }^{1,2}$ (D) and Takahiko Miyazaki ${ }^{1,2}$ \\ 1 Department of Advanced Environmental Science and Engineering, Faculty of Engineering Sciences, \\ Kyushu University, Kasuga-koen 6-1, Kasuga-city 816-8580, Japan; \\ miksik.frantisek.394@m.kyushu-u.ac.jp (F.M.); maeshiro.yuta.678@s.kyushu-u.ac.jp (Y.M.); \\ kyaw.thu.813@m.kyushu-u.ac.jp (K.T.); miyazaki.takahiko.735@m.kyushu-u.ac.jp (T.M.) \\ 2 Research Center for Next Generation Refrigerant Properties (NEXT-RP), International Institute of \\ Carbon-Neutral Energy Research (I2CNER), Kyushu University, 744 Motooka, Nishi-ku 819-0395, Japan \\ * Correspondence: seo.sang.won.731@s.kyushu-u.ac.jp; Tel.: +81-(0)-92-583-7840; Fax: +81-(0)-92-583-7833
}

check for updates

Citation: Seo, S.; Mikšík, F.; Maeshiro, Y.; Thu, K.; Miyazaki, T. Performance Evaluation of an Adsorption Heat Pump System Using MSC-30/R1234yf Pair with the Impact of Thermal Masses. Appl. Sci. 2021, 11, 2279. https://doi.org/ 10.3390/app11052279

Academic Editor:

Amjad Anvari-Moghaddam

Received: 2 February 2021

Accepted: 28 February 2021

Published: 4 March 2021

Publisher's Note: MDPI stays neutral with regard to jurisdictional claims in published maps and institutional affiliations.

Copyright: (c) 2021 by the authors. Licensee MDPI, Basel, Switzerland. This article is an open access article distributed under the terms and conditions of the Creative Commons Attribution (CC BY) license (https:/ / creativecommons.org/licenses/by/ $4.0 /)$.

\begin{abstract}
In this study, we evaluated the performance of low Global Warming Potential (GWP) refrigerant R1234yf on the activated carbon (MSC-30) for adsorption heating applications. The adsorption isotherms of MSC-30/R1234yf were measured using a constant-volume-variable-pressure (CVVP) method from very low relative pressure to the practical operating ranges. The data were fitted with several isotherm models using non-linear curve fitting. An improved equilibrium model was employed to investigate the influence of dead thermal masses, i.e., the heat exchanger assembly and the non-adsorbing part of the adsorbent. The model employed the model for the isosteric heat of adsorption where the adsorbed phase volume was accounted for. The performance of the heat pump was compared with MSC-30/R134a pair using the data from the literature. The analysis covered the desorption temperature ranging from $60{ }^{\circ} \mathrm{C}$ to $90^{\circ} \mathrm{C}$, with the evaporation temperature at $5{ }^{\circ} \mathrm{C}$ and the adsorption temperature and condensation temperature set to $30^{\circ} \mathrm{C}$. It was observed that the adsorption isotherms of R1234yf on MSC-30 were relatively lower than those of R134a by approximately $12 \%$. The coefficient of performance (COP) of the selected pair was found to vary from 0.03 to 0.35 depending on the heat source temperature. We demonstrated that due to lower latent heat, MSC-30/R1234yf pair exhibits slightly lower cycle performance compared to the MSC-30/R134a pair. However, the widespread adaptation of environmentally friendly R1234yf in automobile heat pump systems may call for the implementation of adsorption systems such as the direct hybridization using a single refrigerant. The isotherm and performance data presented in this work will be essential for such applications.
\end{abstract}

Keywords: adsorption heat pump cycle; isotherm fitting; activated carbon; MSC-30; R1234yf

\section{Introduction}

Adsorption heat pump systems have gained attention during the last few decades as alternatives to conventional systems to solve environmental issues through energy savings. The field itself saw its biggest progress during the global energy crisis in the 1970s. Later, it has become an attractive alternative for specific environmental problems after the signature of the universal agreement, which restricts the manufacturing and usage of environmentally harmful refrigerants (CFCs, HCFCs) in the 1980s [1-3]. Hence, in this connection with the global changes, the present studies mainly concentrate on reducing the Global Warming Potential (GWP) due to the burning of fossil fuels for heating and cooling applications. Moreover, because almost half of the primary energy in the residential sector is consumed for cooling and heating, conventional mechanical compression heat pump systems are seen as serious energy consumers and play an essential role in energy demand composition. Despite being an attractive alternative, adsorption systems, unfortunately, show some key drawbacks such as low performance and bulkiness. Due to these 
problems, the research in recent years has concentrated on improving performance and efficiency. For instance, finding "adsorbent-adsorbate" pairs with higher performance and optimization of adsorption cycles operation strategy are constantly being reported [4-7].

Among the tested materials, activated carbon (AC) has often been adopted as a major adsorbent. Many studies have demonstrated adsorption on several kinds of AC with high surface area and volumetric uptake, high thermal conductivity, controllable pore structure, and good thermal stability [8-16]. Many researchers have reported the adsorption isotherms of the activated-carbon-refrigerant pairs for the adsorption systems as well. Habib et al. [17] experimentally measured AC/R134a and AC/R507A pairs to evaluate adsorption kinetics of R134a and R507A on the pitch-based activated carbon, namely MSC-30 (often known as Maxsorb III), by the constant volume variable pressure (CVVP) method, like in this work. Using the aforementioned MSC-30, Uddin et al. [18] presented an investigation of performance of an adsorption-compression hybrid refrigerant system using AC with several refrigerants for the mechanical vapor compression system (R1234yf, R134a, R152a, R1234ze) and ethanol for the adsorption cycle. Therewithal, MSC-30 proved to have especially good adsorption properties when used with ethanol as a refrigerant $[19,20]$. Later on, Azahar et al. [21] evaluated several kinds of adsorbent-adsorbate pairs consisting of activated carbon and refrigerant for the adsorption heat pump system showing an improved model for the isosteric heat of adsorption. Furthermore, Azahar et al. [21] also demonstrated a thermodynamic model for the isosteric heat of adsorption. That is an important factor since many industrial applications utilize the adsorption process [22-25]. Nevertheless, their AC's drawback was a lower adsorption quantity, when the maximum adsorption quantity was only around $0.3 \mathrm{~kg} / \mathrm{kg}$, which was approximately a quarter of calcium chloride capacity, showing the highest reported adsorption quantity of $1.2 \mathrm{~kg} / \mathrm{kg}[26,27]$.

The potential of a typical adsorbent-adsorbate pair is often assessed using an equilibrium cycle analysis when the adsorption isotherm data are available. The equilibrium cycle analysis is a quick methodology to compare the cycle performance of various working pairs and useful for the working pair selection. An important parameter that is sometimes overlooked in such analyzes or not paid proper attention to is the effect of thermal mass. Gluesenkam et al. [28] have recently pointed out that the thermal masses of individual components can considerably influence many adsorption heat pump systems' performance and should be carefully evaluated. Gluesenkamp et al. [28] utilized three metrics factors: mass ratio, specific thermal mass, and effective specific heat to discuss the influence on the system performance. Given the complexity of the actual adsorption system, it is rather difficult to determine the exact value of the thermal masses for the adsorbent and heat exchanger materials. Nevertheless, the adsorption system's performance with respect to the thermal mass ratio (adsorbent to heat exchanger mass) will be an important parameter for the working pair selection. Here, we attempted an improved equilibrium cycle analysis considering the thermal mass impacts to comprehensively estimate the performance of selected activated carbon/refrigerant pairs.

MSC-30, formerly known as Maxsorb III, is well defined and widely accepted as the high-performance activated carbon; however, the amount of research data and information available about this material's performance with various refrigerants is still limited. Therefore, we performed a detailed measurement of MSC-30/R1234yf pair's isotherms by the constant-volume-variable-pressure (CVVP) method at different temperatures to obtain the necessary data for the performance analysis. For comparison's sake, we adopted the isotherm data of MSC-30 with R134a from Loh [29]. Using this working pair, Loh [29] reported an experimental and theoretical study of the high-pressure adsorption chiller. MSC-30 and ACF A20 were selected as adsorbents, while R134a, R410a, and R507A were the adsorbates. Here, we focus on investigating the potential of MSC-30/R1234yf for adsorption heating applications comparing with the MSC-30/R134a pair. It was noted that R1234yf is considered a direct replacement for R134a for the automobile air-conditioning system. Thus, isotherm and performance data will be useful for the hybrid AC (mechanical 
+ adsorption) systems using a single refrigerant, unlike the work of Uddin et al. [18]. For the purpose of the energy performance analysis, we re-fitted the isotherm experimental data from our measurements and the data from Loh [29] by the adsorption isotherm models of Type I and critically examined their suitability. We followed the conventional approach as well and used the more common models (Freundlich model, Langmuir model) in contrast with more developed models such as the Toth model, D-R model, and D-A model.

\section{Experiment}

\subsection{Materials}

2.1.1. Thermophysical Properties of the Adsorbents (MSC-30)

The physical properties of MSC-30 in this work were measured and compared with some previously reported data such as those of Thu et al. [30], presenting methane's adsorption characteristics on MSC-30 using the gravimetric method and showing good agreement with the published specifications. Thu et al. [30] evaluated essential aspects for the adsorption process on MSC-30, such as pore surface area, micropore volume, and pore size distribution, using the standard procedure of nitrogen adsorption at a cryogenic temperature of liquid nitrogen under atmospheric pressure $\left(-196{ }^{\circ} \mathrm{C} / 1 \mathrm{~atm}\right)$. The specific heat capacity necessary for the system performance analysis was adopted from the work of Azahar et al. [21].

The surface characteristics of the MSC-30 were examined through the standard nitrogen adsorption on a surface characterization instrument (3Flex, Micromeritics, Norcross, GA, USA) at $-196{ }^{\circ} \mathrm{C}$. The samples' preparation consisted only of a degassing step at $200^{\circ} \mathrm{C}$ for $8 \mathrm{~h}$ in a high vacuum prior to the measurement. The SEM images were taken by the field emission scanning electron microscope (JSM-7900F, JOEL, Peabody, MA, USA). The heat capacity was measured by a differential scanning calorimetry (DSC) instrument (DSC-60, Shimadzu, Kyoto, Japan) by comparing the measured values to a known standard sample of alpha-alumina according to the method in Mikšík et al. [31]. Furthermore, to obtain the temperature-dependent relation, a polynomial function in a simple form of $c_{p, A d s}(T)=a_{0}+a_{1} T+a_{2} T^{2}+a_{3} T^{3}+a_{4} T^{4}$ was used in this study.

The nitrogen adsorption/desorption isotherm on MSC-30 is given in Figure 1. Based on these adsorption data, the surface area has been obtained through the BET isotherm analysis given Equation (1), which is the linear transformation of BET isotherm as a function of relative pressure:

$$
\frac{1}{c\left(\frac{P_{0}}{P}-1\right)}=\frac{1}{c_{m}}+\frac{C-1}{c_{m} C}\left(\frac{P}{P_{0}}\right)
$$

where $c$ is the adsorbed amount, $c_{m}$ is the monolayer adsorbed amount, and $P$ and $P_{0}$ are the absolute pressure and saturation pressure, respectively. From filling in the data of adsorbed amount $c$ and respective absolute pressures $P$, we can obtain the $y$-axis intercept $Y_{I t c}$, the first term of the right side in Equation (1), and the slope $Y_{S l p}$, the second term of the right side. The standard model then calculates the surface area $S_{B E T}$ using the terms $Y_{S l p}$ and $Y_{I t c}$ as follows:

$$
S_{B E T}=\frac{a_{N 2} N_{A}}{V_{M}\left(Y_{S l p}+Y_{\text {Itc }}\right)}
$$

where $N_{A}$ is the Avogadro constant, $V_{M}$ is the standard molar volume $\left(V_{M}=22.414 \mathrm{dm}^{3} / \mathrm{mol}\right)$, and $a_{N 2}$ is the cross-sectional area of the adsorbed molecule planar to the adsorbed surface, here the nitrogen molecule. We choose to follow the general recommendation for the nitrogen molecular cross-sectional area of nitrogen molecules $a_{N 2}=0.162 \mathrm{~nm}^{2}$ on carbonbased adsorbents [32]. The resulting BET isotherm parameters are calculated based on the linear fit in the relative pressure region of $P / P_{0}=0.05$ to 0.3 . The resulting BET constant is $C=147.968$, with the monolayer adsorption equal to $c_{m}=31.29 \mathrm{mmol} / \mathrm{g}$. The correlation coefficient of the BET linear fitting showed a very good agreement with the experimental 
data and was estimated to be 0.99924 . The correlation coefficient $R$ was calculated using the standard formula:

$$
R=\frac{\sum\left(x_{i}-\bar{x}\right)\left(y_{i}-\bar{y}\right) / N}{\sigma_{x} \sigma_{y}} \sigma_{p}=\sqrt{\frac{\sum\left(p_{i}-\bar{p}\right)^{2}}{N}}
$$

where, $x_{i}$ and $y_{i}$ are the individual values of the $x$-axis and $y$-axis, while $\bar{x}$ and $\bar{y}$ are the mean values of the sample sets. $N$ states the size of the sample set. The standard deviations $\sigma_{x}$ and $\sigma_{y}$ were calculated based on the lower term $\sigma_{p}$ from set Equation (3), where $p$ takes the form of the respective indexed values of $x$ and $y$ axes.

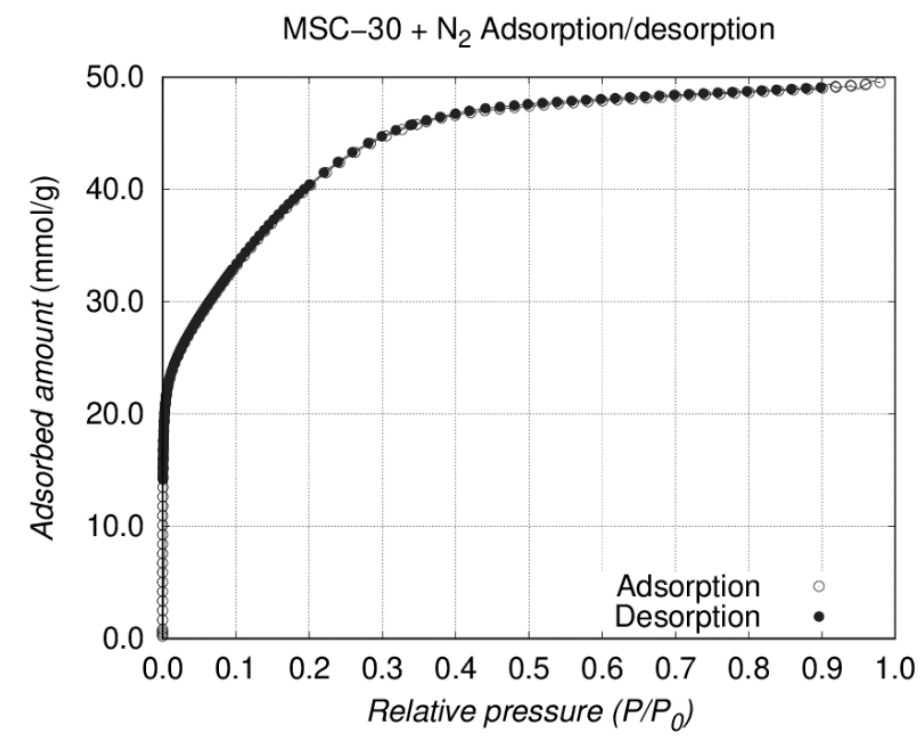

Figure 1. Nitrogen adsorption/desorption isotherm $\left(T_{i s o}=-196^{\circ} \mathrm{C}\right)$.

The mean pore diameter was calculated from the pore size distribution based on the non-local density functional theory (NLDFT) model provided with the surface characterization instrument's software (3Flex Version 3.01). The NLDFT model was calculated using density-dependent weighting functions and slit-like pore geometry according to the prescription of Tarazona et al. [33]. Similarly, the pore volume is obtained by comparing the NLDFT results with the experimental data, again with the assumption of slit-like pores, which are typical for activated carbon materials. Due to the shape and because the regularity of the pores is highly variable for the activated carbon materials, a geometrical comparison cannot be provided as a general rule. The summary of the material properties of MSC-30 is presented in Table 1.

Table 1. The main characteristics of MSC-30.

\begin{tabular}{ccccc}
\hline & $\begin{array}{c}\text { Surface Area } S_{B E T} \\
\left(\mathbf{m}^{2} / \mathbf{g}\right)\end{array}$ & $\begin{array}{c}\text { Mean Pore Diameter } d_{p} \\
(\mathbf{n m})\end{array}$ & $\begin{array}{c}\text { Pore Volume } V_{p} \\
\left(\mathbf{c m}^{\mathbf{3}} / \mathbf{g}\right)\end{array}$ & $\begin{array}{c}\text { Heat Capacity } c_{p} \\
(\mathbf{J} /(\mathbf{g ~ K}))\left(\mathbf{2 5}{ }^{\circ} \mathbf{C}\right)\end{array}$ \\
\hline MSC-30 & 3203 & $\left(1.71^{\dagger}\right) 2.03 \ddagger$ & 1.721 & 0.77 \\
\hline
\end{tabular}

${ }^{\dagger}$ D-A Method; ${ }^{\ddagger}$ non-local density functional theory (NLDFT)—pore volume.

Figure 2 shows the SEM images of MSC-30. Based on the SEM observation, we estimate the mean particle size of the MSC-30 to be around $150 \mu \mathrm{m}$, while most of the particles can be found in the range between $100 \mu \mathrm{m}$ to $200 \mu \mathrm{m}$. Figure 2 shows a detailed surface structure with visible ridges across the particles that were observable in all examples. Based on the structure of MSC-30, we can expect that these macroporous openings $(>0.05 \mu \mathrm{m}$, IUPAC 
classification) will increase the diffusion rate of the adsorbate inside the particles and overall will have a positive effect on the adsorption kinetics.

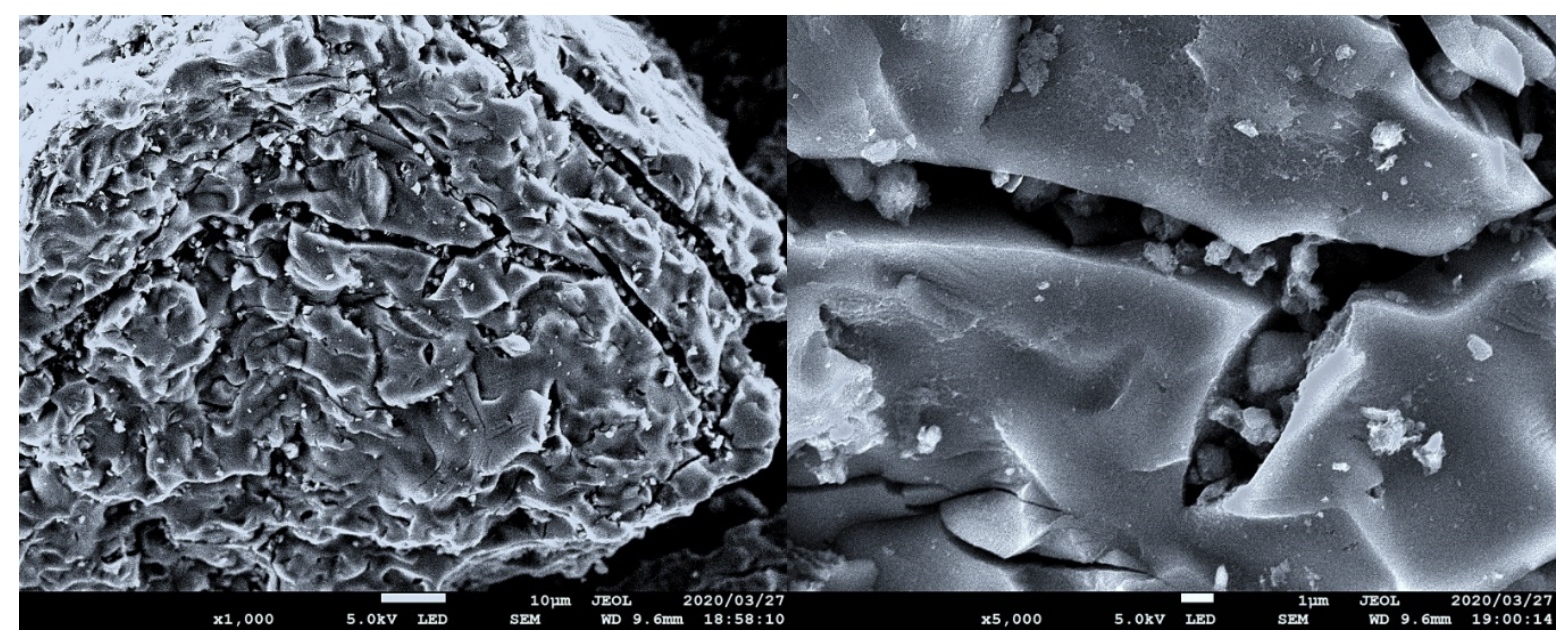

Figure 2. SEM images of the MSC-30 activated carbon.

\subsubsection{Thermophysical Properties of Adsorbates (R1234yf)}

The hydrofluorocarbon (HFC) refrigerant R134a (norflurane) has been used for a long time, before the fluorinated hydrocarbon was developed to replace the currently banned R12 (dichloro-difluoro-methane) in various applications. R134a is a common refrigerant for some chillers and is widely used in automotive air-conditioning systems [34]. However, due to its high GWP, a gradual phasing out in favor of refrigerants with lower environmental impacts is expected. The fluorinated hydrocarbon R1234yf is one of the refrigerants proposed to replace R134a in automotive air-conditioning and several other applications; the basic thermophysical properties of R1234yf are listed in Table 2 [35]. We can see that R1234yf has a considerably lower GWP, and from the perspective of environmental effects is, therefore, safer to use when compared to its replacement target. Recently, Thu et al. [36] reported the conventional vapor compression cycle performance of R1234yf in a binary mixture with R32. They noted that HFC refrigerant R1234yf has a remarkably small volumetric capacity compared to HFC refrigerants such as R134a. However, this is problematic because the volumetric capacity is closely related to the performance of the conventional mechanical vapor compression cycle. Therefore, this work aims to analyze some alternative application methods of R1234yf, specifically, the adsorption heat pump systems.

Table 2. The main properties of R1234yf [35].

\begin{tabular}{cc}
\hline Chemical Formula & $\mathbf{C}_{\mathbf{3}} \mathbf{H}_{\mathbf{2}} \mathbf{F}_{\mathbf{4}}$ \\
\hline Molecular Weight $(\mathrm{g} / \mathrm{mol})$ & 114 \\
ODP ${ }^{\dagger}$ & - \\
GWP(100 years) ${ }^{\dagger}$ & $<1$ \\
Toxicity ${ }^{\dagger}$ & Non-Toxic \\
Flammability $\ddagger$ & $\bigcirc$ \\
Normal boiling point $\left({ }^{\circ} \mathrm{C}\right)$ & -29.5 \\
Critical temperature $\left({ }^{\circ} \mathrm{C}\right)$ & 94.7 \\
Critical pressure $(\mathrm{kPa})$ & 3382.2 \\
Saturation Pressure $\left(\right.$ at $\left.30^{\circ} \mathrm{C}\right)(\mathrm{kPa})$ & 783.51 \\
Latent heat of evaporation $\left(\right.$ at $\left.30{ }^{\circ} \mathrm{C}\right)(\mathrm{kJ} / \mathrm{kg})$ & 141.24 \\
Vapor Density (at $\left.30^{\circ} \mathrm{C}\right)(\mathrm{kg} / \mathrm{m})$ & 43.73 \\
\hline${ }^{\dagger}$ IPCC Fifth Assessment Report, $2014(\mathrm{AR} 5) ;{ }^{\ddagger} \mathrm{ASHRAE34-2013} \mathrm{Designation} \mathrm{and} \mathrm{safety} \mathrm{classification} \mathrm{of} \mathrm{refrigerants.}$
\end{tabular}




\subsection{Experimental Apparatus}

The isotherm of the selected adsorbent/adsorbate pair was measured using a constantvolume-variable-pressure (CVVP) apparatus to analyze the adsorption isotherm. The apparatus was designed and set up in the Thermal Energy Conversion Systems (TECS) laboratory of Kyushu University. Figure 3 shows the schematic diagram of the experimental setup. The CVVP method by general knowledge, is a differential manometric method of establishing the adsorption amount by estimating the pressure difference between the beginning and the end of the adsorption steps. The experimental device consists of the adsorption cell (V-Tech, $150 \pm 2 \mathrm{~cm}^{3}$ ), the load cell (304L-HDF4-1000, Swagelok, Solon, OH, USA, $1011 \pm 8 \mathrm{~cm}^{3}$ ), the liquid cell (304L-05SF4-150, Swagelok), and tube assembly (SUS304BA $\varphi 6.35 \mathrm{~mm}$ (1/4 in), Mecc Technia, Nishinoyama, Japan). The adsorption and the load cells' temperatures were maintained by a constant temperature water bath (UB50, Lauda). The vacuum pump (VPC-050A, ULVAC Kiko, Saito, Japan) was used for the evacuation of the experimental system, while the vacuum levels were determined by a vacuum gauge (PG-D5A, Sato vac. Inc, Tokyo, Japan). Two absolute pressure transducers (2MPa, Kyowa, Tokyo, Japan, PA-20KB; 100 kPa, Swagelok PTI-S-MA.1-22AQ-T) were used to acquire the equilibrium pressure during the adsorption isotherm measurements. K-type thermocouples were installed to measure the temperature in all cases. The data from temperature and pressure measurements were logged using a data acquisition system (MX100, Yokogawa Electric, Tokyo, Japan). Before starting the experiment, all thermocouples were calibrated against a master temperature sensor (Standard platinum resistance thermometer, Chino R800-2).

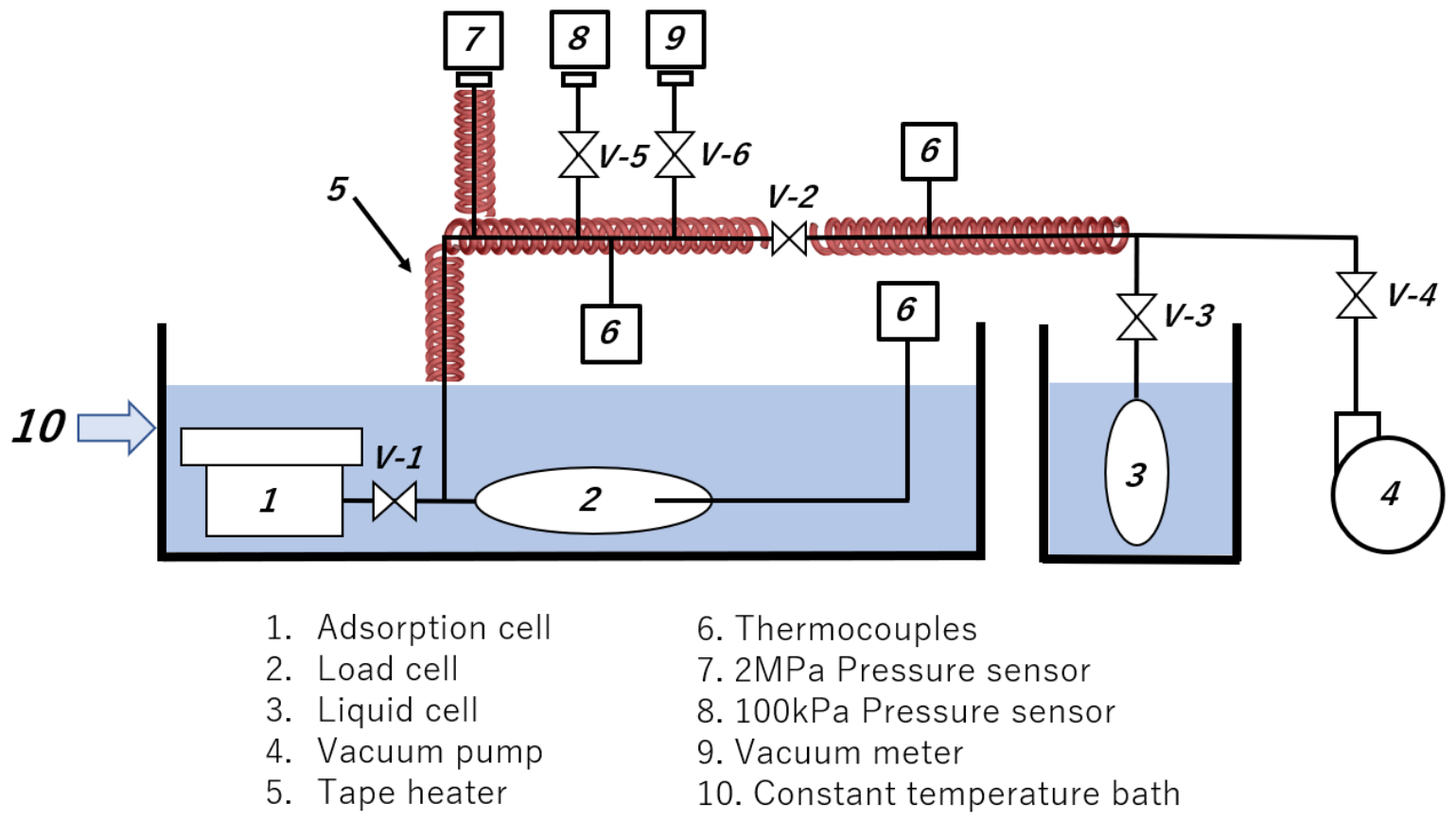

Figure 3. Constant-volume-variable-pressure experimental apparatus.

\subsection{Experimental Procedure and Data Reduction}

Many researchers have already analyzed several hypothetical adsorption isotherms and kinetics models to estimate the behavior of adsorbate-adsorbent working pairs. For example, Singh et al. [37] presented the adsorption isotherms and kinetics of $\mathrm{CO}_{2}-\mathrm{CSAC}$ pair for cooling applications. In their study, the rate of R1234yf adsorbed by CSAC (coconut shell-based activated carbon) was evaluated by a similar CVVP experimental setup with a starting pressure of around $0.01 \mathrm{kPa}$.

Here, we placed the adsorption cell (1) and the load cell (2), in Figure 3, in a constanttemperature bath while we implemented the liquid cell (3) for charging of the refrigerant. 
The temperature of the bath in the case of the Liquid cell (3) was regulated using a constant temperature circulator (CTP-3000, EYELA Co., Ltd., Tokyo, Japan) to control the initial charging pressure of the refrigerant (adsorbate). The actual charging pressure of the refrigerant (adsorbate) was regulated by adjusting the control valve (V-3). A ribbon heater (E16, Sakaguchi E.H VOC, Tokyo, Japan) was utilized to maintain the tube temperature at a constant temperature of about $5{ }^{\circ} \mathrm{C}$ above the saturation point at the given isothermal conditions. Before starting the measurement, the experimental system was thoroughly evacuated for around $12 \mathrm{~h}$ to ascertain constant initial conditions for each isothermal experiment.

During the individual experiments, we first charged the refrigerant (adsorbate) into the Load cell (2) from the Liquid cell (3) at the targeted pressure. The amount of refrigerant in the load cell at the constant temperature was calculated using the volume of the cell, equilibrium pressure data, and temperature data. The adsorption of the refrigerant started by opening the valve (V-1), separating the adsorption and the load cell. The adsorption uptake was subsequently estimated, as explained before, from the calculated amount based on the pressure change before and after the adsorption step at constant temperature and volume. For further details about this procedure, interested readers may refer to the works of Chua et al. [38], Ng et al. [39], and Loh [29].

The amount of refrigerant(adsorbate) $m_{i}$ in the load cell with constant volume $V_{\text {Load_cell }}$ before the adsorption step $i$ can then be estimated as:

$$
m_{i}=\rho_{\text {ref }, i}(P, T) V_{\text {Load_cell }}
$$

where $\rho_{r e f, i}(P, T)$ is the density of the refrigerant at a given temperature $T$ and pressure $P$.

The void space of the adsorption cell can be calculated by the following formula:

$$
V_{\text {Void }}=V_{\text {ads_cell }}-\frac{m_{a d s}}{\rho_{a d s}}-v_{\mu} m_{a d s}
$$

where $v_{\mu}$ and $\rho_{a d s}$ are the micropore volume and the density of the adsorbent, and $m_{\text {ads }}$ is the mass of the adsorbent. Hence, the mass of refrigerant in the adsorption cell (in the void space) is estimated:

$$
m_{\text {Void }}=\rho_{\text {ref }}(P, T) V_{\text {Void }}
$$

Finally, the net uptake $m_{\text {Uptake }}$ by the adsorbent at the adsorption step can be calculated by Equation (7), and the specific adsorption amount $c$ is obtained simply by Equation (8):

$$
\begin{gathered}
m_{\text {Uptake }}=m_{i}-\rho_{\text {ref }}\left(V_{\text {Load }_{\text {cell }}}+V_{\text {Void }}\right) \\
c=\frac{m_{\text {Uptake }}}{m_{\text {ads }}}
\end{gathered}
$$

We performed the measurement for four different isothermal conditions applicable to the intended heat pump cycles. All procedures were identical for all the isotherm measurements. The data measurements were performed from $20^{\circ} \mathrm{C}$ to $70^{\circ} \mathrm{C}$ with a step of $10^{\circ} \mathrm{C}$. In the range of $20^{\circ} \mathrm{C}$ to $40^{\circ} \mathrm{C}$, the measurements were performed two times to evaluate the consistency and accuracy.

\section{Mathematical Modeling}

\subsection{Adsorption Isotherm Model of Type I}

In this study, we adopted adsorption isotherm models of Type I typical for the activated carbon with various refrigerants. Type I models emphasize the adsorbent-adsorbate interactions and are essential to predict the adsorption process on materials with high surface area and prevalent volume in the microporous region. We compared some of the classical models, such as the Freundlich model and Langmuir model, with more developed models (Toth, D-R, and D-A). The experimental data were fitted using the non-linear curve 
fitting method coded in Python, and we calculated the projected fitting error of the model in regards to the experimental data.

To fully comprehend the whole adsorption region of the selected adsorption pair, we set the first adsorption step of the MSC-30/R1234yf pair to a lower pressure, well below $1 \mathrm{kPa}$. However, typically at a lower pressure, the adsorption uptake is relatively small, and the changes in the recorded pressure are burdened by the intrinsic instrument error and resolution of the pressure gauges. Moreover, even though the actual adsorbed amount is comparatively small with respect to the adsorbent's full capacity, the relative error can be rather high. Hence, for better clarity, we presented the final mean relative deviation as an average. That can be done because the working region of the calculation of the specific heating power and the coefficient of performance is applicable for relatively higher pressure where experimental data show typically only a fractional deviation from the model.

\subsubsection{Freundlich Model}

The Freundlich adsorption model is an empirical model developed to fit the isothermal variations of gas adsorption on a solid surface. While the original model was created simply to project the experimental data, later, it was derived theoretically as well [37,38]. Hatch et al. [40] expressed that the Freundlich model can successfully describe the sorption process from an aqueous media as well as gas adsorption on porous surfaces. Moreover, Hatch et al. [40] pointed out the key feature of this model that it accounts for the intermolecular interactions between adsorbates and can imply heterogeneity of adsorption sites. However, the simplicity of the model cannot correctly comprehend more intricate adsorption systems and, therefore, typically shows significantly lower accuracy than the Toth model or the D-A model. For this reason, it has not frequently been used in recent research. Equation (9) shows the Freundlich model in its typical form:

$$
w=w_{0}\left(\frac{P}{P_{0}}\right)^{1 / n}
$$

where $w$ and $w_{0}$ are the equilibrium uptake and the maximum uptake in $\mathrm{kg} / \mathrm{kg}$, respectively. $P / P_{0}$ is the relative pressure of adsorbate normally described as the ratio of absolute pressure $P$ to the saturation pressure $P_{0}$ at the given temperature.

\subsubsection{Langmuir and Toth Model}

The classical Langmuir and Toth models are still widely used in the current adsorption systems to describe the adsorption process and characterize the adsorption conditions. Furthermore, the Toth model is often used together with the D-A model, and together they are frequently used in various forms and with the addition of some corrections for the adsorbed phase. Saha et al. [41] summarized common adsorption models for adsorption cooling and heating applications and provided an overview of some of the water- and ethanol-based systems' capabilities.

Equations (10)-(13) express the Langmuir and Toth model and expand the necessary parameters in the form that will be used in this work:

$$
\begin{gathered}
w=w_{0} \frac{b P}{1+b P} \\
w=w_{0} \frac{b P}{\left(1+(b P)^{t}\right)^{1 / t}} \\
b=b_{0} \exp \left(\frac{Q_{a}}{R T}\right) \\
t=t_{a}+\alpha\left(1-\frac{T_{0}}{T}\right)
\end{gathered}
$$


The Toth model fundamentally builds on the Langmuir model by extending the original Langmuir Equation (10) with an additional parameter, the Toth isotherm's exponent $t$ as demonstrated in Equation (11). The interaction constant $b\left(\mathrm{kPa}^{-1}\right)$, generally denoted as $K$ in the Langmuir isotherm, has a similar meaning in both models, and it is related to the binding affinity of the respective adsorbent/adsorbate system. The preceding additional Toth exponent in Equation (11) then corrects the model in relation to the heterogeneity of the surface. From the form of the equation, it is clear that once the exponent $t$ reaches unity, signifying high homogeneity of the surface, the Toth equation takes the shape of the Langmuir equation. Since adsorption is a fully reversible process, the amount of energy exchanged with the environment can be described as a change in the system's energy potential formally explained by Gibbs free energy $\Delta G^{\circ}=-R T \ln \left(K / K_{0}\right)$. Substituting the equilibrium constant $K$ and the reference state $K_{0}$ with the interaction constant $b$ and reference state $b_{0}$, we get Equation (12). In this modification, the energy term $Q_{a}$ corresponds to the adsorption energy as a combination of phase change enthalpy and binding energy. Lastly, the $R$ and $T$ terms are the common gas constant and thermodynamic temperature, respectively. The additional Toth isotherm constant can also be expressed as a function of temperature, as in Equation (13). The constant parameters $t_{a}$ and $\alpha$ do not carry theoretical meaning and serve only as fitting parameters [42]. In this work, we assume the reference temperature $T_{0}=298.15 \mathrm{~K}$.

\subsubsection{D-R Model}

The D-R (Dubinin-Radushkevich) model is typically applied to express the adsorption mechanism with a Gaussian energy distribution onto a heterogeneous surface [40,41]. In contrast with the Langmuir surface adsorption, the D-R model also accounts for the porous structure for the adsorbent and includes the microporous filling. Dada et al. [43] presented studies of Langmuir, Freundlich, Temkin, and D-R isotherm models of equilibrium sorption of $\mathrm{Zn}^{2+}$ onto phosphoric acid-modified rice husk. They mentioned that the $\mathrm{D}-\mathrm{R}$ model often offers successful fitted values for high-solute activities and the intermediate range of concentration data. The $\mathrm{D}-\mathrm{R}$ model is given as:

$$
w=w_{0} \exp \left(-K\left[R T \ln \frac{P_{0}}{P}\right]^{2}\right)
$$

where $w$ and $w_{0}$ is the specific equilibrium uptake per unit of the adsorbent and maximum specific uptake, respectively. $K$ is the constant parameter for each adsorbent and adsorbate system. $P / P_{0}$ is the standard relative pressure of adsorbate, and $T$ and $R$ are the thermodynamic temperature and gas constant, respectively.

\subsubsection{D-A Model}

The D-A (Dubinin-Asthakov) model has been developed as a more generalized model of the D-R model and builds on the potential concept of Polanyi $[44,45]$. Currently, it is one of the most applied models, and it is adopted in many studies due to its high accuracy and simplicity. To further expand the field of application of the D-A model, Azahar et al. [21] have recently formulated a method to obtain the isosteric heat of adsorption using the parameters of the D-A model. The following Equations (15) and (16) express the D-A model without the adsorbed volume correction and with the adsorbed volume correction, respectively.

$$
\begin{aligned}
& w=w_{0} \exp \left[\left(-\frac{R T \ln \left(P_{0} / P\right)}{E}\right)^{n}\right] \\
& w=\frac{C_{0}}{v_{a}} \exp \left[\left(-\frac{R T \ln \left(P_{0} / P\right)}{E}\right)^{n}\right]
\end{aligned}
$$

In Equations (15) and (16), $w$ is once more the specific uptake at the equilibrium expressed in $\mathrm{kg} / \mathrm{kg}$, and $w_{0}$ and $C_{0}$ are the maximum uptake and maximum volumetric 
uptake in $\mathrm{kg} / \mathrm{kg}$ and $\mathrm{m}^{3} / \mathrm{kg}$, respectively. Finally, the $E$ is the adsorption energy and $n$ is similar to the Toth equation the heterogeneity factor. It is worth noting that once the heterogeneity factor becomes $n=2$, the $\mathrm{D}-\mathrm{A}$ isotherm formally becomes the $\mathrm{D}-\mathrm{R}$ isotherm. Then, both of the models practically share the same adsorption potential $\varepsilon$ dependent on the natural logarithm of the inversed relative pressure:

$$
\epsilon=R T \ln \left(\frac{P_{0}}{P}\right)
$$

To express the volumetric adsorption, another parameter for the limited compressibility of the liquid phase has to be taken into account, especially when working at high pressures (often known as adsorbed phase volume correction). With this consideration, the density of the adsorbed phase $v_{a}$ can be written as follows [46]:

$$
v_{a}=\left\{\begin{array}{l}
v_{b} \exp \left(\alpha\left[T-T_{b}\right]\right), \text { if } P_{\text {Trip }}<P_{A m b} \\
v_{\text {Trip }} \exp \left(\alpha\left[T-T_{\text {Trip }}\right]\right), \text { otherwise }
\end{array}\right.
$$

The thermal expansion coefficient $\alpha$ can be expressed using three approaches, which are the constant value of $0.0025,1 / T$, and a model that was suggested by Nikolayev and Dubinin [47], which is shown in the following Equation (19):

$$
\alpha=\left\{\begin{array}{l}
\frac{\ln \left(\frac{b_{w}}{v_{b}}\right)}{T_{\text {Crit }}-T_{b}}, \text { if } P_{\text {Trip }}<P_{A m b} \\
\frac{\ln \left(\frac{b_{w}}{v_{b}}\right)}{T_{\text {Crit }}-T_{\text {Trip }}}, \text { otherwise }
\end{array}\right.
$$

where $b_{w}$ is the van der Waals volume of the adsorbate in $\mathrm{cm}^{3} / \mathrm{mol}$.

\subsection{Isosteric Heat of Adsorption from the $D-A$ Model}

\subsubsection{Ideal Approach}

The isosteric heat of adsorption $q_{s t}$ is normally expressed in the form of heat released by the diminutive amount of bulk molecules adhered to the finite surfaces of the adsorbent at the constant temperature and pressure. Typically, the general expression of the isosteric heat of adsorption can be written as the following Equation (20) [48-50].

$$
q_{s t}=T\left(v_{g}-v_{a}\right) \frac{d P}{d T}
$$

When the adsorbed phase volume is neglected, and the ideal gas assumption is invoked as in most of the cases, the equation takes the following form:

$$
q_{s t}=R T^{2} \frac{d \ln P}{d T}
$$

At the same time, the specific enthalpy of evaporation $q_{f g}(\mathrm{~kJ} / \mathrm{kg})$ can be expressed as follows:

$$
q_{f g}=R T^{2} \frac{d \ln P_{0}}{d T}
$$

From the D-A equation, $\ln P$ is expressed as follows:

$$
\ln P=-\frac{E_{a}}{R T}\left[\ln \left(\frac{w_{0}}{w}\right)^{\frac{1}{n}}\right]+\ln P_{0}
$$

Finally, combining Equation (21) with Equation (23) and after some algebraic manipulation, the ideal approach for the heat of adsorption is obtained in Equation (24):

$$
q_{s t}=q_{f g}+E_{a}\left[\ln \left(\frac{w_{0}}{w}\right)\right]^{1 / n}
$$


where the second term then combines the activation energy of the adsorption pair $E_{a}$ with adsorption potential expressed as a reversed ratio of the maximum adsorption $w_{0}$ over the isosteric amount $w$. This means the energy yield is naturally higher at less surface coverage.

\subsubsection{Azahar, F.H.M. Model}

As mentioned above, Azahar et al. [21] presented an improved model to express the isosteric heat of adsorption using the parameters of the D-A model. They offered three types of non-ideal models that rely on the pressure of the adsorbate and adsorption temperature. In this study, we have adopted the high-pressure model $\left(T<T_{\text {Crit }}\right)$ to analyze the performance of the adsorption system. The model of Azahar et al. [21] is expressed in Equation (25):

$$
\begin{gathered}
q_{s t}=P v_{g}\left(\frac{T}{P_{0}} \frac{d P_{0}}{d T}+\ln \frac{P_{0}}{P}\right), \text { Low } P(\text { Partial vacuum }) \\
q_{s t}=P\left(v_{g}-v_{a}\right)\left[\frac{T}{P_{0}} \frac{d P_{0}}{d T}+\ln \frac{P_{0}}{P}+\frac{\alpha}{n}\left(\frac{E}{R}\right)^{n}\left(T \ln \frac{P_{0}}{P}\right)^{1-n}\right], \operatorname{High} P\left(T<T_{\text {Crit }}\right) \\
q_{s t}=P\left(v_{g}-v_{a}\right)\left[k+\ln \frac{P_{0}}{P}+\frac{\alpha}{n}\left(\frac{E}{R}\right)^{n}\left(T \ln \frac{P_{0}}{P}\right)^{1-n}\right], \operatorname{High} P\left(T>T_{\text {Crit }}\right)
\end{gathered}
$$

where $v_{a}$ is the density of the adsorbed phase in $\mathrm{m}^{3} / \mathrm{kg}$ and $v_{g}$ is the equilibrium of gaseous phase density of the adsorbent again in $\mathrm{m}^{3} / \mathrm{kg}$. Parameter $E(\mathrm{~J} / \mathrm{mol})$ is the characteristic energy that is specific for the given adsorption pair and the heterogeneity factor remains as $n$ from the D-A equation. At the same time, $d P_{0} / d T$ can be expressed as the following Equation (26) based on the Clausius-Clapeyron equation for the solid to liquid transition:

$$
\frac{d P_{0}}{d T}=\frac{q_{f g}}{\left(v_{g}-v_{a}\right) T}
$$

where $P_{0}$ is the saturation pressure at the phase change temperature $T$ and $v_{g}$ and $v_{a}$ are the transition volumes in the gas phase and adsorbed phase, respectively.

\subsection{Equilibrium Analysis of the Adsorption Heat Pump Cycle}

Many studies have already adopted the idea of the adsorption phenomenon into heat pump systems. Aristov [51] presented the concept of optimal adsorbents' parameters for adsorptive cooling/heating applications focusing on the limitations and potential of the recent materials, and Pinheiro et al. [52] reviewed the current situation of the heating applications that are using adsorption heat pumps. Here, it is necessary to point out that most of the research so far has focused mostly on cooling applications. However, heating applications are crucial for sustainable living conditions as well and will be an essential part of future energy transformations. Therefore, in this study, we focus on the heating part of the adsorption heat pump system. The cycle schematics of the adsorption heat pump system are shown in the diagram in Figure 4.

Formerly, Cacciola et al. [53] expressed the detailed thermodynamic processes of the ideal adsorption cycle, and this ideal approach of a single bed adsorption cycle configuration is also shown for our intended system in Figure 4 by the solid line. It consists of four sequential thermodynamic processes: I. Pre-heating $(b-c)$, II. Desorption (c-d), III. Pre-cooling ( $\mathrm{d}-\mathrm{a})$, and IV. Adsorption $(\mathrm{a}-\mathrm{b})$. $Q_{\text {input }}$ is the heat supply to the adsorption bed heat exchanger, and it is used for heating the bed during the desorption process. $Q_{\text {cond }}$ is the heat released in the condenser, $Q_{\text {out }}$ is the heat produced during the adsorption process extracted from the bed, and $Q_{e v a}$ is the heat supply to the evaporator during evaporation of the adsorbate. 


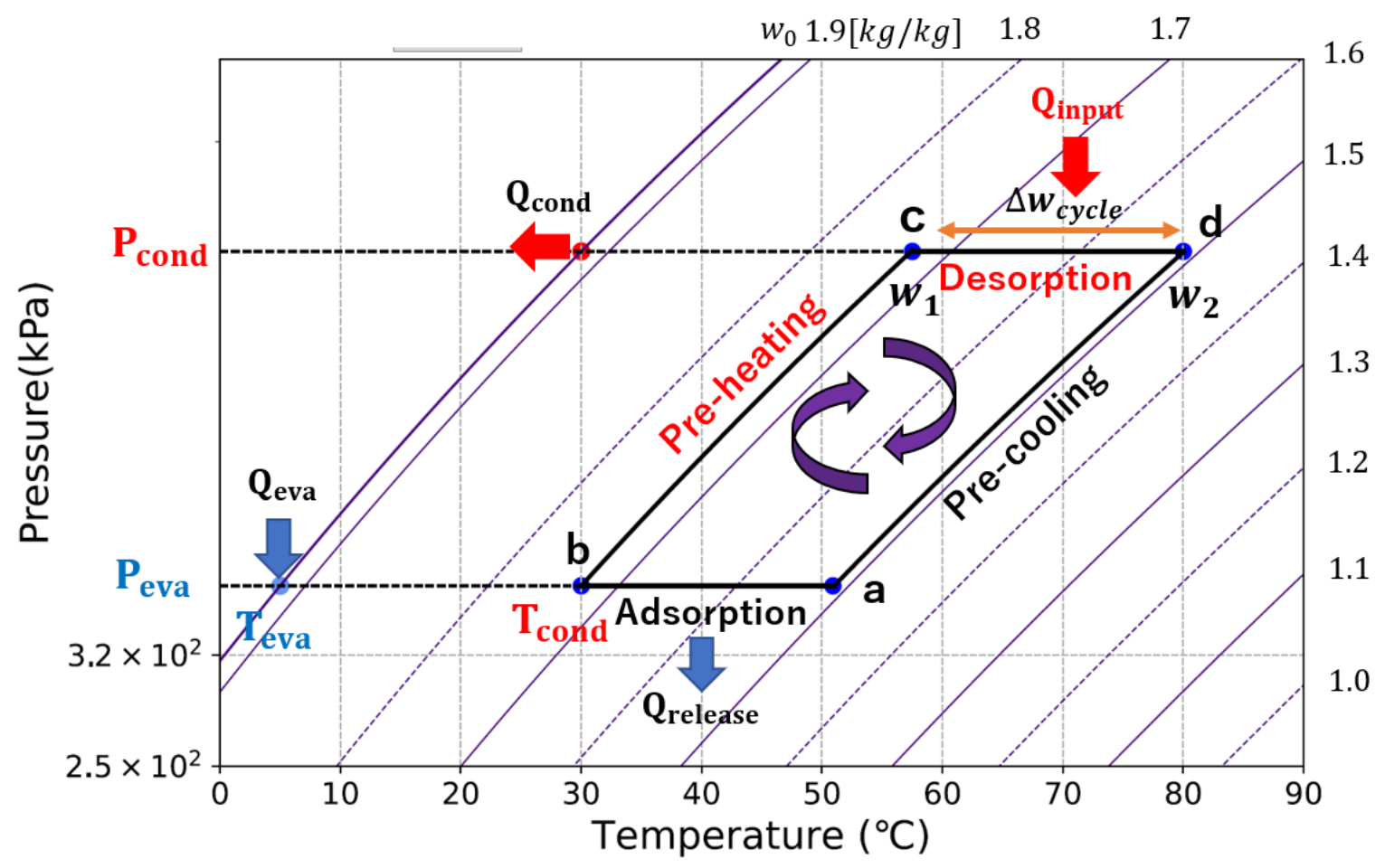

Figure 4. Schematics of the adsorption heat pump cycle.

Heat input of the cycle is the same as for the cooling mode; however, in the heating mode, instead of specific cooling power (SCP) $(\mathrm{kJ} / \mathrm{kg})$, specific heating power (SHP) $(\mathrm{kJ} / \mathrm{kg})$ is used for the calculation. The following Equations show the calculation of the SHP:

$$
\begin{gathered}
\mathrm{SHP}=Q_{\text {cond }}+Q_{a d s} \\
Q_{\text {cond }}=\left(q_{f g}\left(T_{\text {cond }}\right)\right)\left(w_{\text {max }}-w_{\text {min }}\right) \\
Q_{\text {ads }}=q_{s t}\left(w_{\text {max }}-w_{\text {min }}\right)
\end{gathered}
$$

The coefficient of performance (COP) of heating mode can be then express as:

$$
\mathrm{COP}_{\text {Eq,heating }}=\frac{S H P}{Q_{I N}}
$$

where $Q_{I N}$ is the total heat input of the adsorption system. $Q_{I N}$ consists of two parts: latent heat and sensible heat. Equations (31)-(33) show the necessary calculation for the heating mode COP:

$$
\begin{aligned}
& Q_{I N}=Q_{\text {Lat }}+Q_{S e n} \\
& Q_{\text {Lat }}=q_{\text {st }}\left(T_{\text {des },}, p_{\text {cond }}\right) \int_{T_{P h}, P_{\text {cond }}}^{T_{\text {des }}, P_{\text {cond }}} d w \\
& Q_{S e n}=\frac{c_{p, a d s}\left(T_{d e s}\right)+c_{p, a d s}\left(T_{a d s}\right)}{2 \int_{T_{a d s}}^{T_{d e s}} d T}+w_{\max }\left[\frac{c_{p, a}\left(T_{P h,} p_{c o n d}\right)+c_{p, a}\left(T_{a d s}, p_{e v a}\right)}{2 \int_{T_{\text {ddd }}}^{T_{P h}} d T}\right] \\
& +\int_{T_{P h,}, P_{\text {cond }}}^{T_{\text {des }}, P_{\text {cond }}} d w\left[\frac{c_{p, a}\left(T_{\text {des },}, P_{\text {cond }}\right)+c_{p, a}\left(T_{P h,}, p_{c o n d}\right)}{2 \int_{T_{P h}}^{T_{d e s}} d T}\right]+\frac{M_{H X, B e d}}{M_{a d s}}\left[\frac{c_{p, H X}\left(T_{\text {des }}\right)+c_{p, H X}\left(T_{a d s}\right)}{2 \int_{T_{a d s}}^{T_{d e s}} d T}\right]
\end{aligned}
$$

The latent heat $Q_{\text {Lat }}$ in Equation (32) is simply calculated as a function of the adsorption heat $q_{s t}$ in the working range of the desorption temperature $T_{d e s}$ and pre-heating temperature $T_{P h}$ under the given pressure conditions $P_{\text {cond }}$. The sensible heat $Q_{S e n}$ is then calculated as the addition of heat contained by all major parts in the working temperature range. Given the unity factor of the specific heat of the adsorber $c_{p, a d s}$ used in the gener- 
alized calculation, the heat contained by the heat exchanger can be expressed directly as the ratio to the adsorbed amount $M_{H X, B e d} / M_{\text {ads }}$ combined with the specific heat of the adsorption bed material. Finally, the amount of previously adsorbed refrigerant is accounted for as well through its specific heat $c_{p, a}$ and specific adsorption amount function $w(T, P)$, which is based on the adsorption isotherm modeling.

Azahar et al. [21] presented their model with the specific heat capacity of the adsorbent as a temperature-dependent variable. Hence, in this work, we also use a similar approach and introduce the specific heat as a function of temperature $c_{p, a d s}(T)$. The function is modeled as a polynomial expansion of a higher degree to satisfy a good fit with the experimental data. Previously, the experimental data for the specific heat capacity of MSC-30 were presented by Uddin [54] in the form of 4th order polynomial $c_{p, a d s}(T)=a_{0}+a_{1} T+a_{2} T^{2}+a_{3} T^{3}+a_{4} T^{4}$. The measurement methods and 3rd polynomial equation for calculating the specific heat of MSC-30 for this study are mentioned in the sections above. Table 3 shows the fitted coefficients for calculating the specific heat capacity of MSC-30, which we adopted from our measurement.

Table 3. The coefficient of specific heat capacity of the adsorbent.

\begin{tabular}{cc}
\hline Coefficient & MSC-30 \\
\hline$a_{0}$ & 0.76627 \\
$a_{1}$ & $3.8768 \times 10^{-4}$ \\
$a_{2}$ & $6.2667 \times 10^{-6}$ \\
$a_{3}$ & $7.2600 \times 10^{-8}$
\end{tabular}

Gluesenkamp et al. [28] have presented thermal masses of heat exchangers with several types. In this study, we consider only one material for the assembly, aluminum. Equation (34) shows the specific heat of aluminum, which is adopted from Solberg et al. [55,56]:

$$
c_{p, H X}(T)=(4.94+0.00296 T) \times 4184 / 26.981539
$$

where $c_{p, H X}$ is the specific heat capacity of heat exchangers. The temperature conditions of the adsorption heating cycle for the purposes of the analysis are then summarized in Table 4.

Table 4. The temperature condition of the adsorption cycle.

\begin{tabular}{cccc}
\hline $\begin{array}{c}\text { Desorption } \\
\text { Temperature }\end{array}$ & $\begin{array}{c}\text { Adsorption } \\
\text { Temperature }\end{array}$ & $\begin{array}{c}\text { Condensation } \\
\text { Temperature }\end{array}$ & $\begin{array}{c}\text { Evaporation } \\
\text { Temperature }\end{array}$ \\
\hline $60 \sim 80^{\circ} \mathrm{C}$ & $30^{\circ} \mathrm{C}$ & $30{ }^{\circ} \mathrm{C}$ & $5{ }^{\circ} \mathrm{C}$ \\
\hline
\end{tabular}

\section{Results and Discussion}

\subsection{Transient Data}

Typically, in an actual adsorption system, the optimum adsorption capacity of the adsorbent would be determined from the experimentally defined equilibrium data of the given system. This is dependent on several factors, including the adsorption bed geometry, binding material, thickness of the adsorption material, etc. However, with the information on the adsorption kinetics of the material, we can predict such behavior with sufficient precision, or at least exclude the effect of the adsorption material and consider it as negligible. Figure 5 shows the transient data of the adsorption kinetics at $30^{\circ} \mathrm{C}$. 


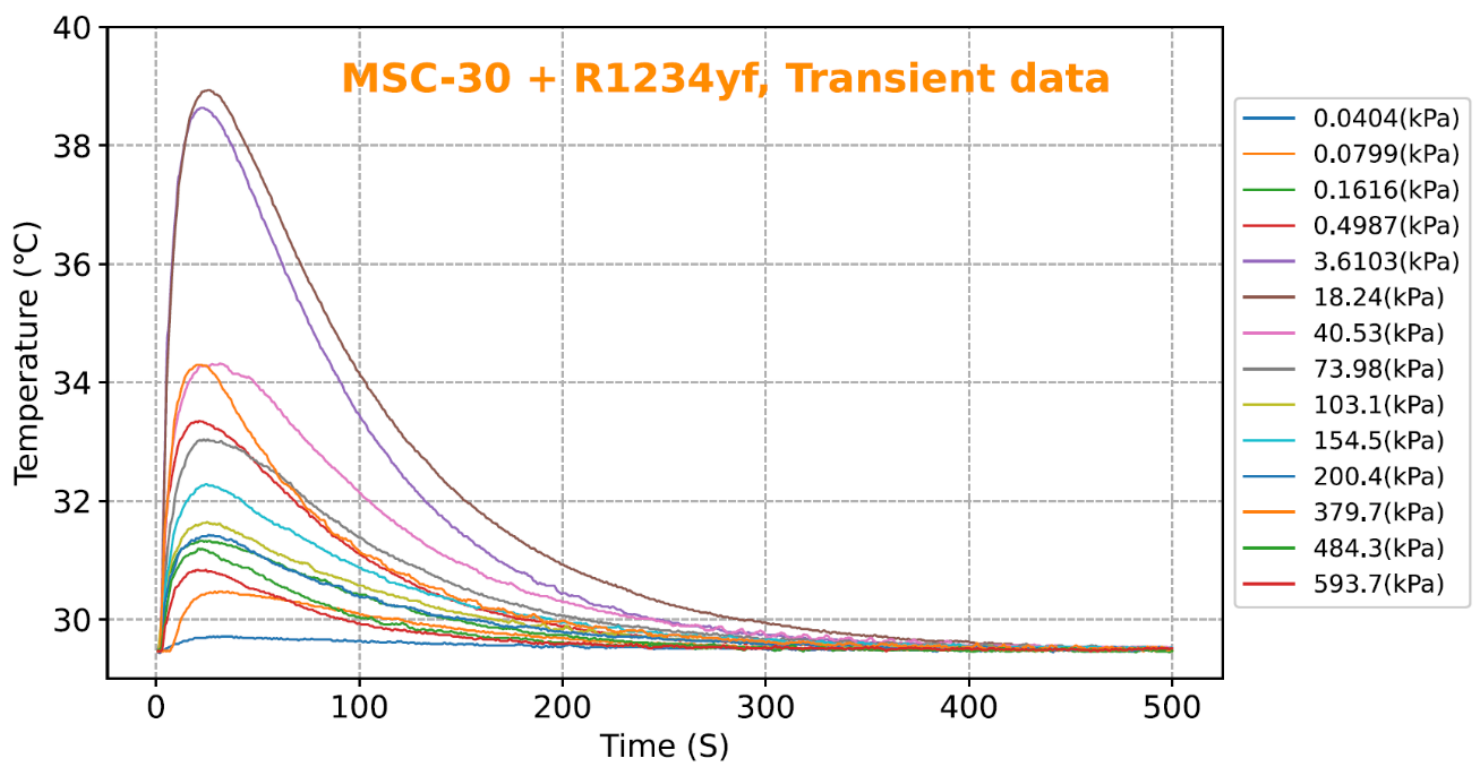

Figure 5. The transient temperature of MSC-30/R1234yf pair at adsorption isotherm $\left(30^{\circ} \mathrm{C}\right)$.

The transient data show the temperature elevation during the exothermic adsorption process in time and clearly demonstrate the equilibrium time dependency. We observed that it takes around $400 \mathrm{~s}$ to stabilize the temperature after starting the adsorption process fully. This is comparable to the previous experimental findings on MSC-30/R134a pair or MSC-30/R32 as reported by Habib et al. [17] and Askalany et al. [57], respectively. The transient data described by Askalany et al. [57] may arguably suggest faster kinetics of MSC-30/R32 pair; however, the method used was adjusted, and the whole process is controlled with emphasis on temperature stability, which explains the increase in the apparent adsorption rate. Accordingly, if the temperature of the adsorbent is allowed to increase excessively, the adsorption equilibrium will be shifted downwards, and the equilibrium can be reached only once the material reaches the target temperature again. In this work, the highest temperature of the system reached around $8{ }^{\circ} \mathrm{C}$, corresponding to the highest adsorption increases. From Figure 5, it is apparent that the lower values the temperature reached from the set temperature, the faster the equilibration occurred. Typically, in the beginning, the adsorption temperature increased for a while by self-heating, while in most of the pressure cases, this effect reached a peak within around 20 to $30 \mathrm{~s}$. As the whole process is exothermic, thermal energy is constantly being ejected during the procedure until the equilibrium state is reached in about 400-500 s. Similar results, when the transient data peak around the $20 \mathrm{~s}$ mark, were also demonstrated by Loh [29] when expressing the kinetic data for MSC-30/R134a pair (at $5{ }^{\circ} \mathrm{C}$ ), MSC-30/R410a pair (at $15^{\circ} \mathrm{C}$ ), and MSC-30/R507a pair (at $5{ }^{\circ} \mathrm{C}$ ). In this context, the important finding is that the adsorption kinetics of the R1234yf are comparable to the previously reported refrigerants on MSC-30 adsorbent.

\subsection{Adsorption Isotherm Fitting}

The experimental data of MSC-30/R1234yf pair of this work and the reference data on MSC-30/R134a pair [29] were re-fitted with the Freundlich, Langmuir, Toth, D-R, and D-A isotherm models. All of these models describe the Type I isotherm model as recommended by the IUPAC. The root-mean-square error (RSME) method, which is also presented by Wang et al. [58], is used to analyze the fitting or regression error. It is defined in the following formula:

$$
100 \sqrt{\sum_{i=1}^{n} \frac{\left(a b s\left(\exp _{i}-\text { model }_{i}\right)\right)^{2}}{N}}
$$


where $\exp _{i}$ is the experimental value at point $i$, and model $_{i}$ is the calculated value given by the model at point $i$. The fitted results by the isotherm models and error values are summarized in the Supplementary Materials.

Currently, the Toth model and the D-A model are possibly the most applied models for refrigerants/activated carbon systems and used for adsorption isotherm analysis thanks to their accuracy and simplicity. However, the Freundlich, Langmuir, and D-R models are also still being used due to their historical development and the fact that they can provide, together with the current models, some additional insight based on the relevant adsorption theories. From the perspective of classical models' accuracy, the empirical Freundlich model offers $8.53 \%$ error for MSC-30/R134a and a virtually identical 8.52\% error for the MSC-30/R1234yf pair, while the simple Langmuir model offers $6.53 \%$ error for MSC-30/R134a and 8.92\% error for MSC-30/R1234yf. In comparison with the conventional Toth model, these fitting errors are about two times higher for MSC-30/R134a, and more than five times higher for MSC-30/R1234yf, while the actual fit error values for the Toth model are as low as $3.06 \%$ and $1.66 \%$, respectively. The fitting of the Toth model for MSC-30/R1234yf is shown in Figure 6.

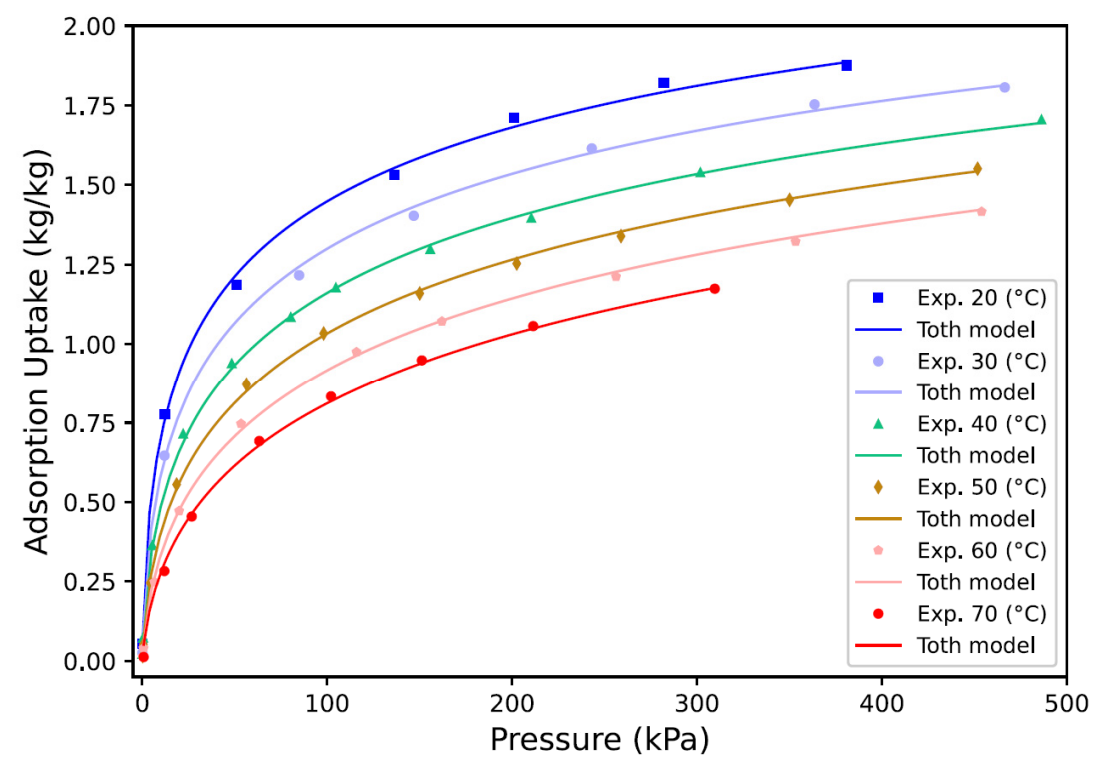

Figure 6. Isotherm fitting results of the Toth model for MSC-30/R1234yf.

A relatively high fitting error is observed using D-R model with $9.82 \%$ error for MSC-30/R134a pair and 7.56\% error for MSC-30/R1234yf pair, while its limitation can be obviously seen in the fixed exponent factor. This problem is closely addressed in the development of the D-A model introducing the heterogeneity exponent factor $n$, which becomes a fittable parameter. This substantially increases the accuracy of the model in comparison to the D-R model, although this is at the expense of an additional fitting constant. Furthermore, from Tables S1 to S4 in the Supplementary Materials, we can notice that the adsorbed phase volume correction can improve the fitting accuracy, which was also observed by others [21]. We can see that the goodness of fit in the case of MSC-30/R134a pair is decreasing in a sequence of $\alpha=\mathrm{ND}$ model, $\alpha=1 / \mathrm{T}$, and $\alpha=0.0025$, with respective error values of $4.75 \%, 5.44 \%$, and $5.63 \%$, while the D-A model without volume correction provides with a fitting error of $3.77 \%$. On the other hand, the data also show a notable increase in accuracy for all the volume corrections of the MSC-30/R1234yf pair; nonetheless, no significant variation between the individual correction approaches manifested, and the fitting error obtained was approximately $2.5-2.6 \%$ in every case. An example of fitting the D-A model on the MSC-30/R1234yf pair where $\alpha=1 / \mathrm{T}$ is presented in Figure 7. Overall, the Toth temperature-dependent model shows better fitting errors for both pairs. 


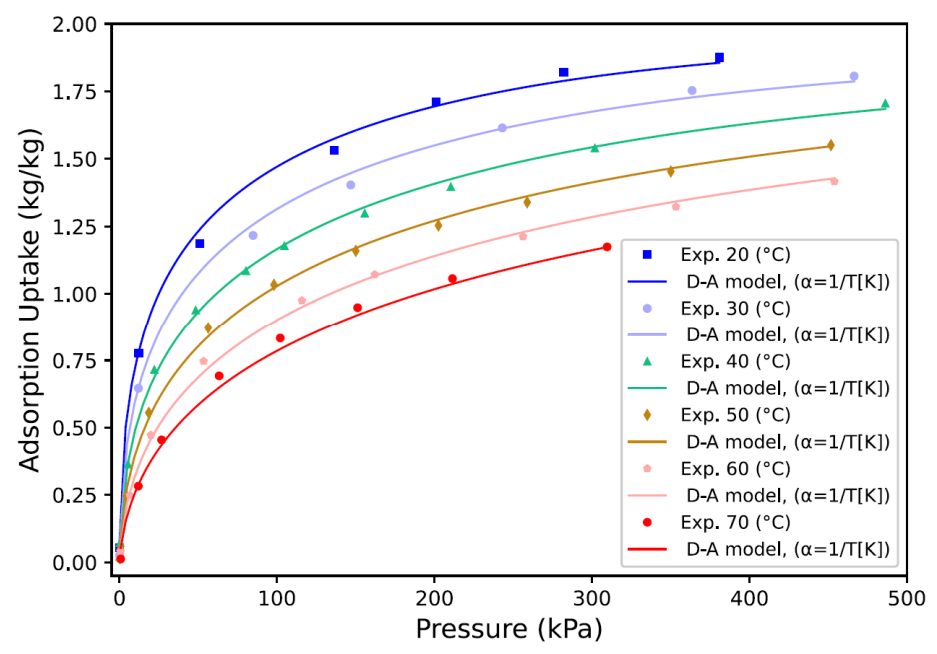

Figure 7. Isotherm fitting results of the D-A model $(\alpha=1 / \mathrm{T}[\mathrm{K}])$ for MSC-30/R1234yf.

\subsection{Comparison with MSC-30/R134a Pair}

\subsubsection{Adsorption Potential}

Based on the D-A mode method in Equation (17), we obtained the adsorption potentials $\epsilon$ for several different refrigerant/activated carbon pairs. The adsorption potential dependence shown in Figure 8 expresses the chemical potential difference between the adsorbent and the adsorbate, and it can be expressed by the differential change of free energy in a reversible isotherm transition from the liquid phase to the adsorbate phase. We have observed the adsorption potential of both pairs is remarkably similar. Therefore, the evaporation enthalpies of R1234yf and R134a make the main difference in the isosteric heat of adsorption. At the saturation point of $30^{\circ} \mathrm{C}$ (at equilibrium), the specific enthalpy of evaporation is $141.24(\mathrm{~kJ} / \mathrm{kg})$ in the case of R1234yf [35] and $173.10(\mathrm{~kJ} / \mathrm{kg})$ for R134a [34].

Similarly, Askalany et al. [59] presented the adsorption isotherm analysis and heat of adsorption using the common difluoromethane (R32) on activated carbon powder (ACP) of type MCS-30 and activated carbon fiber (ACF) of type A-20. As demonstrated in Figure 8, R32 shows a higher adsorption potential of the adsorption uptake than the two other refrigerants, which is later compensated by the actual uptake capacity. It is, however, necessary to mention that in comparison to R1234yf, the R32 operates at significantly higher pressures, especially when used for heating, and poses a certainly non-negligible GWP.

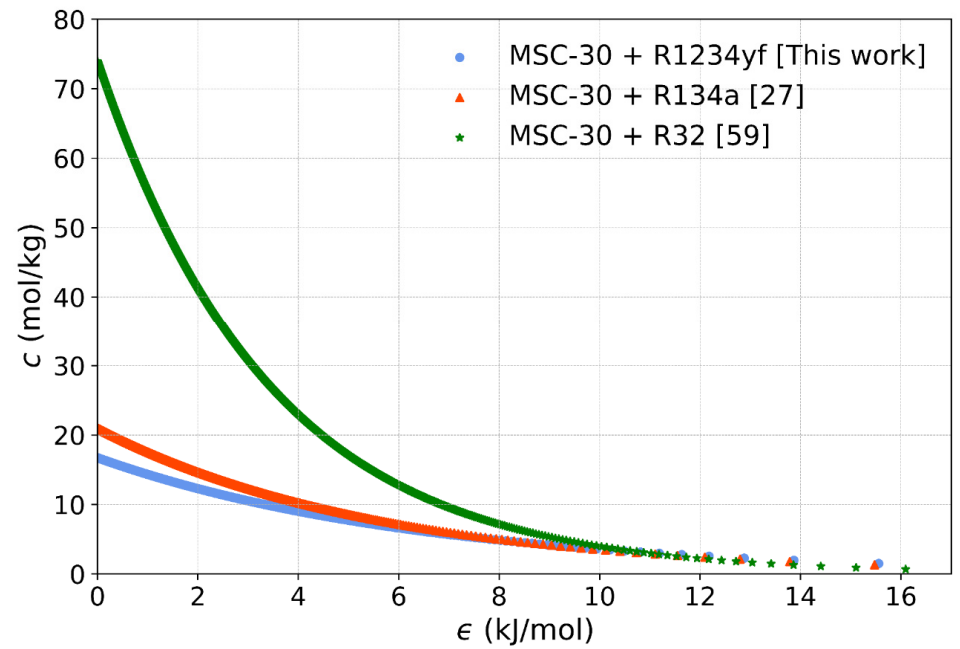

Figure 8. Adsorption potential $\epsilon$ at $20^{\circ} \mathrm{C}$ using the parameters of D-A model $(\alpha=1 / \mathrm{T}[\mathrm{K}])$. 


\subsubsection{Isosteric Heat of Adsorption}

Figure 9 shows the isosteric heat of adsorption for the MSC-30/R134a and MSC30/R1234yf pairs, respectively. We can see that MSC-30/R134a shows higher values than MSC-30/R1234yf. Moreover, Azahar's model [21] always demonstrates a higher value in both cases. This increase is attributed to the pressure correction presented in Equation (25) trying to take into account the actual pressure change, which is apparently higher than in the case of an ideal gas and is intrinsic for the phase change from gas to the adsorbed form. Consequently, with the increasing fugacity of the gas, the difference between ideal behavior and experimental finding becomes more obvious, bringing up the necessity for such corrections. This means that these corrections are typically higher with the increasing pressure, as they are affected more by the adsorbed phase as well and are proportional to the adsorption energy increase. In the case of the studied system in this work, MSC-30/R134a and MSC-30/R1234yf, the pressure dependence is very similar, as is the energy difference, which is partially visible by comparison in Figure 9. Likewise, it can be expected that the COP value calculated using Azahar's model [21] will offer a higher value than the ideal approach, since $q_{a d s}$ is calculated as $q_{a d s}=\left(w_{\max }-w_{\min }\right) q_{s t}$. Accordingly, if $q_{s t}$ increases, the specific heating power (SHP) increases as well.

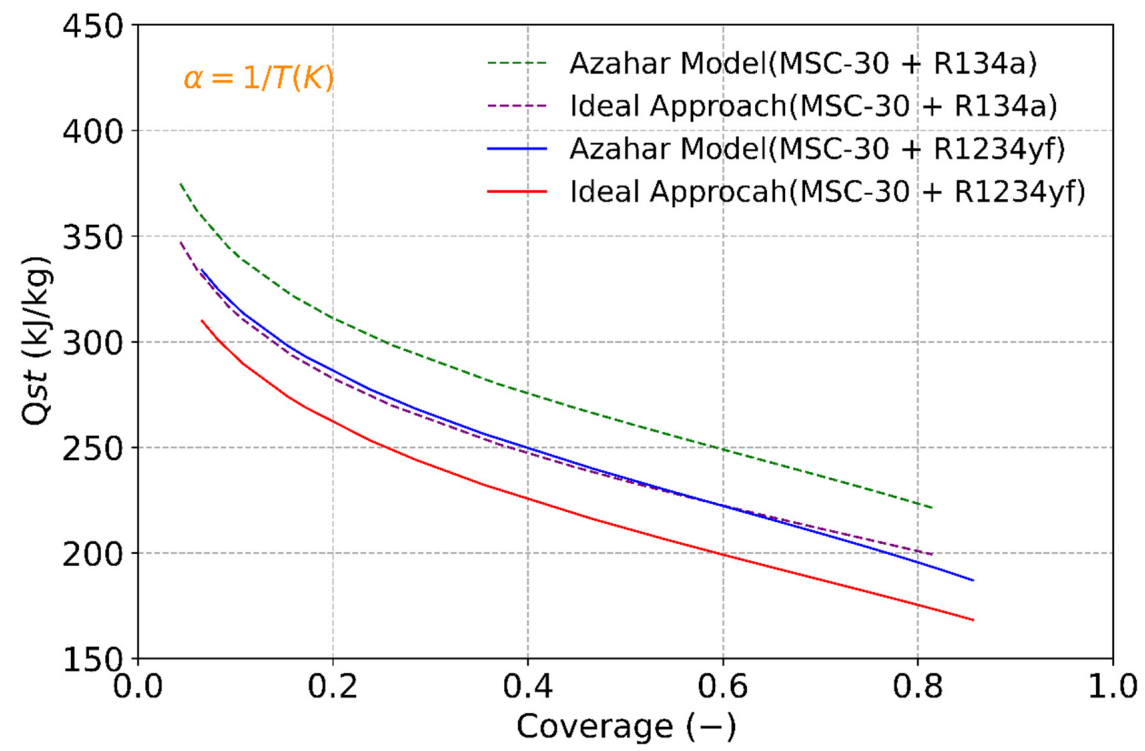

Figure 9. Isosteric heat of adsorption using D-A model for MSC-30/R134a and MSC-30/R1234yf pairs at $30{ }^{\circ} \mathrm{C}$.

\subsubsection{SHP and Thermal Mass-Dependent COP in Adsorption Heating Application}

The major factors describing the adsorption system's performance are typically its heating or cooling capabilities under given conditions, which can be expressed as the specific heating power (SHP) and specific cooling power (SCP). Here, we attempt to analyze the heating capabilities of the MSC-30/R1234yf including the system's thermal mass effect. The SHP of the selected adsorption pair is presented in Figure 10 as analyzed for various desorption temperatures ranging from $60^{\circ} \mathrm{C}$ to $90^{\circ} \mathrm{C}$. Naturally, the SHP of both pairs increases accordingly with increasing desorption temperature, while the final maximum is not too far beyond the selected range. It can be noted that MSC-30/R134a offers higher SHP values than the MSC-30/R1234yf pair in the selected region with increasing tendency. If we look at the formulation of SHP, Equation (27), we can see that the specific heating power is calculated as a combination of condensation heat and adsorption heat, $Q_{\text {cond }}+Q_{\text {ads }}$, when the condensation heat $Q_{\text {cond }}$ is expressed by Equation (28) as heat that is related to the phase change released during the charging phase in the condenser. This approach is common in the literature, and it only requires considering the system to run under constant, uninterrupted conditions, which is the conventional usage. Furthermore, the $q_{g f}$ 
and $q_{s t}$ of R134a are higher than those of R1234yf. Therefore, MSC-30/R134a exhibits significantly higher SHP values than MSC-30/R1234yf. For the calculation of SHP, $w$ values are considered based on the $\mathrm{D}-\mathrm{A}$ model with the volume correction using $\alpha=1 / \mathrm{T}$. Similarly, the specific cooling power (SCP) can be calculated as:

$$
S C P=\left(w_{\max }-w_{\min }\right) q_{f g}\left(T_{e v a}\right)+\int_{c o n d}^{e v a} d h_{f}
$$

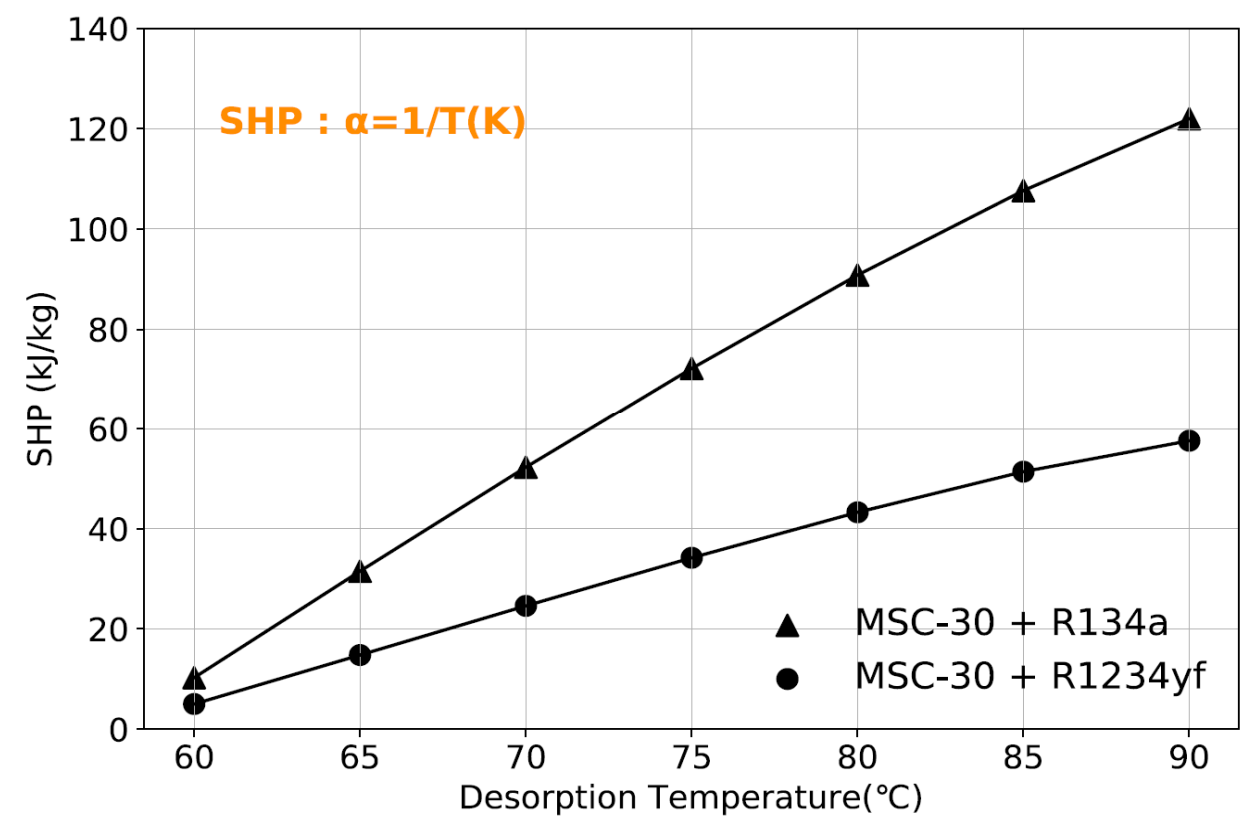

Figure 10. Specific Heating Power (SHP) of MSC-30/R1234yf and MSC-30/R134a pairs (volume correction $\alpha=1 / \mathrm{T}$, using an ideal approach of isosteric heat of adsorption).

In relation to the previous explanation, it can be expected the SCP of MSC-30/R134a to show higher values than MSC-30/R1234yf as well.

The developed equilibrium analysis model that accounts for the effect of thermal masses has been adopted for this study. The results of performance analysis for the selected adsorbent/adsorbate pairs are presented in Figure 11a,b. The COP of the adsorption heat pump cycle from the equilibrium without the thermal mass of the heat exchanger (Bed) is labeled (in the legend) as "Adsorbent only", and as we mentioned before, that is often the case in results presented in most literature sources. In this study, the thermal masses of the heat exchanger have been applied to analyze the performance of the cycle to bring the results closer to the real conditions. Therefore, we have modeled COP values of the full adsorption/desorption cycle with varying thermal mass ratios, i.e., the ratio of the heat exchanger mass to the adsorbent mass. From the work of Gluesenkamp et al. [28], it is apparent that the thermal mass ratio is typically higher for the experimental devices and decreases with the overall capacity of the system. While the highest numbers of the mass ratio for the experimental devices reach 15 20, it is reasonable to expect that the commercial appliances will target the more economical region of $<3 \sim 4$. Here, values from 0 to 3 are presented. 

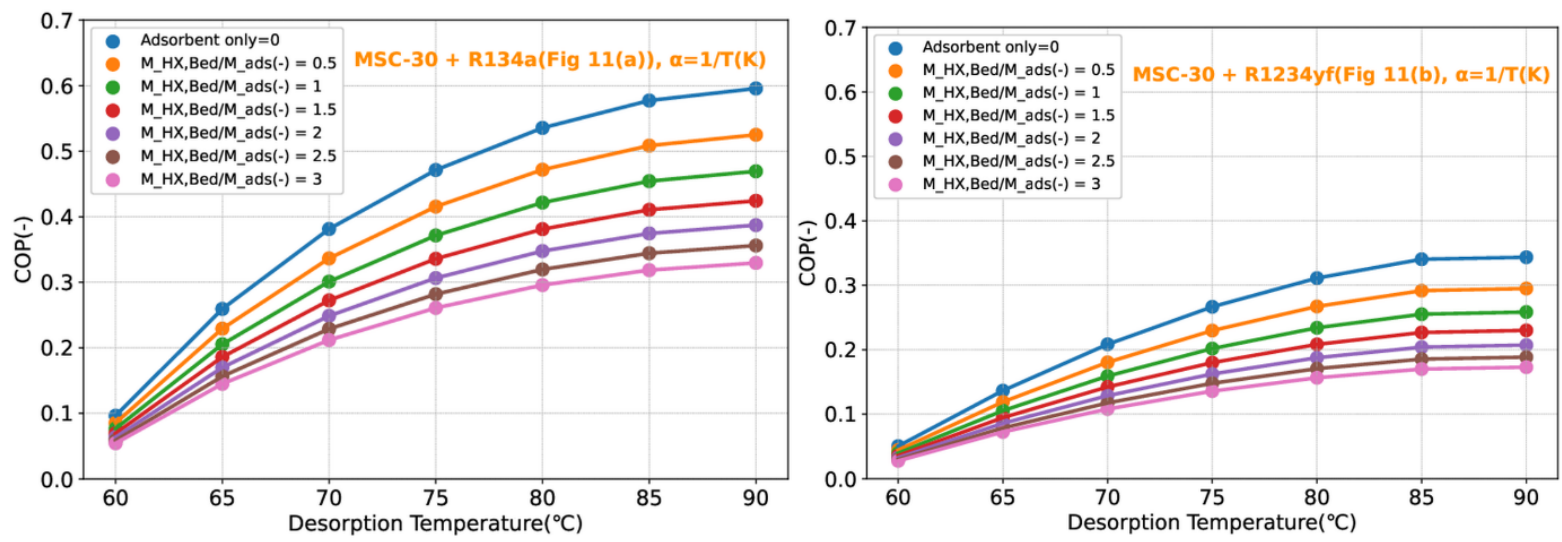

Figure 11. (a) Coefficient of performance (COP) for heating application of MSC-30/R134a (Adsorbent mass ratio) with volume correction $\alpha=1 / \mathrm{T}[\mathrm{K}]$, using the ideal approach of isosteric heat of adsorption. (b) COP for heating application of MSC-30/R1234yf (adsorbent mass ratio) with volume correction $\alpha=1 / \mathrm{T}[\mathrm{K}]$, using the ideal approach of isosteric heat of adsorption.

Figure 11a,b show the resulting COP for different charging temperatures with the 0.5 step of the mass ratio for MSC-30/R134a and MSC-30/R1234yf, respectively. It is clear that the COP degrades with the increased thermal mass of the heat exchanger, and this reduction is more significant at higher desorption temperatures. Although the thermal masses considerably reduce the COP in the continuous regime, we can partially reduce these losses by recycling part of the heat. For example, the excess temperature of the heated adsorber after the regeneration can be used to heat up some parts or deliver the adsorption target temperature of $30^{\circ} \mathrm{C}$. However, this design is highly local condition-specific and, therefore, only the typical usage is considered in this work.

From the results, it is clear that the MSC-30/R134a pair offers better performance in the selected desorption temperature range, especially at higher temperatures. Based on the introduced model, we observed the COP of MSC-30/R134a pair from around 0.05 up to 0.61 through the presented desorption temperatures and thermal mass ratios. Consequently, the model shows the MSC-30/R1234yf pair's COP from around 0.03 to 0.35 in the simulated condition boundaries. Hence, the difference is similar to the SHP results. The major effect, if not counting the thermal mass, on the COP is the evaporation heat, which in the case of R1234yf at $90{ }^{\circ} \mathrm{C}$ is $50.53(\mathrm{~kJ} / \mathrm{kg})$ [34], and that of R134a is $82.49(\mathrm{~kJ} / \mathrm{kg})$ [35]. The actual evaporation heat at $90{ }^{\circ} \mathrm{C}$ of R1234yf is then only around $61 \%$ of the R134a. An additional effect is caused by the net uptake $\left(w_{\max }-w_{\min }\right)$ for the individual adsorption pairs according to the desorption temperature increase, further adding to the gap. Due to these reasons, the $\mathrm{COP}$ of the adsorption cycle does not considerably increase according to the desorption temperature increase. Finally, Figure 12 shows the heating cycle COP using the ideal approach model in comparison with Azahar's model. As already mentioned, the adsorption heat calculations based on Azahar's model show higher values. Hence, the predictions using Azahar's model show slightly better performance of the adsorption pairs, even though that the effect on the actual COP can be seen as fractional.

It is clear that if isosteric heat of adsorption increases, the $\mathrm{COP}$ of a heating application increases as well. However, despite presenting an improved equilibrium model which accounts for the effect of thermal mass and adsorption isotherms, the presented work lacks a detailed study on the adsorption kinetics. Nonetheless, we showed that the kinetics of the MSC-30/R1234yf system is comparable to the more studied adsorption pairs such as MSC-30/R134a and MSC-30/R32. Furthermore, many actual aspects, such as the heat exchanger design or the packing of adsorbent materials, which strongly affect the kinetics performance, together with the total cost, need to be still considered for commercialization in any case. Since R1234yf is getting attention as the alternative refrigerant of R134a because of its low GWP, we believe that the experimental data for the uptake of the MSC-30/R1234yf 
pair, presented in this work, together with theoretical studies, prove to be indispensable for considering the potential of any R1234yf/activated carbon system.

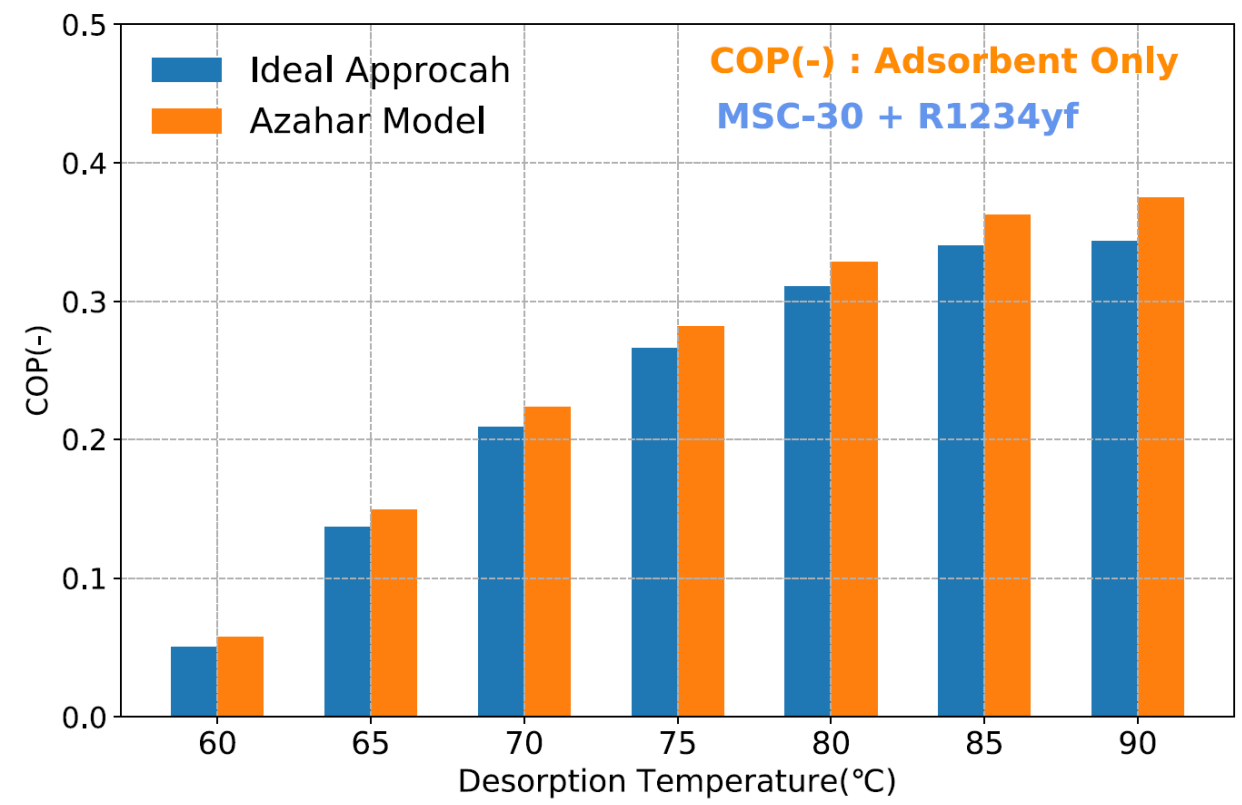

Figure 12. COP for heating application of MSC-30/R1234yf, volume correction $\alpha=1 / \mathrm{T}[\mathrm{K}]$.

Currently, refrigerants are evaluated by their energy efficiency, safety, global warming impact, and economic performance. Although R1234yf gives a trivial GWP below 1, and it belongs to the same safety group with R32 already widely used (ASHRAE34-2013), the economic performance and energy efficiency are comparatively low. Hence, the refrigerant blends with R32, R1123, or $\mathrm{CO}_{2}$ are currently widely researched and are in the scope of our following work.

\section{Conclusions}

The performance of an adsorption heat pump using MSC-30/R1234yf pair was investigated using an improved model that accounts for the impact of thermal masses. The adsorption isotherms of the selected working pair were measured using the constantvolume-variable-pressure apparatus in the temperature range from $20^{\circ} \mathrm{C}$ to $70^{\circ} \mathrm{C}$ starting from a very low pressure of around $0.01 \mathrm{kPa}$. The performance of the heat pump was compared with MSC-20/R134a pair using the published data. The isotherm data were fitted using various adsorption isotherm models of Type I. It was observed that the D-A model with the volume correction and Toth model provide the best fit, typically below $3 \%$ of the fitting error. The improved equilibrium model was selected to supplement the current experimental findings as the references often offer the performance evaluation while neglecting the influence of the thermal masses of heat exchangers. The influence of the thermal mass on the equilibrium cycle was investigated for the ratios in the range from 0 to 3 of the heat exchanger to the adsorbent material.

The presented SHP values of MSC-30/R1234yf are substantially lower than those of the MSC-30/R134a pair under the same temperature conditions. We have shown how the effect of thermal mass is significant for the desorption (regeneration) temperatures. MSC-30/R134a pair offers better performance in the selected desorption temperature range, and the gap in the performance between MSC-30/R1234yf is increasing with increasing temperature. We have also shown that the COP of the MSC-30/R1234yf pair is around 0.05 to 0.35 at the selected desorption temperature range considering only the adsorbent thermal mass. Under the same conditions, MSC-30/R134a pair offers approximately 0.1 to 0.6 COP for the heating application. Furthermore, considering the highest thermal mass ratio of 1:3, the COP can be effectively reduced by half of its value in both cases. Despite a relatively 
poor performance, R1234yf has negligible GWP as compared to the target replacement, i.e., R134a. The present isotherm will be essential for the development of automobile heat pump systems, especially for the direct hybridization using a single refrigerant.

Supplementary Materials: The following are available online at https://www.mdpi.com/2076 $-3417 / 11 / 5 / 2279 / s 1$, Table S1: The parameters of the Freundlich model (Equation (9))-MSC30/R134a experimental data from [29]. Table S2: The parameters of the Langmuir and the Toth model (Equations (10)-(13))-MSC-30/R134a experimental data from [29]. Table S3: The parameters of the D-R model (Equation (14))-MSC-30/R134a experimental data from [29]. Table S4: The parameters of the D-A model (Equations (15) and (16))—MSC-30/R134a experimental data from [29].

Author Contributions: Writing and original draft preparation, Data analysis, S.S.; Investigation, Y.M. and K.T.; Methodology, K.T.; Writing-review and editing, F.M. and K.T.; Review and editing, T.M. All authors have read and agreed to the published version of the manuscript.

Funding: This research received no external funding.

Institutional Review Board Statement: Not applicable.

Informed Consent Statement: Not applicable.

Data Availability Statement: Data is contained within the article or supplementary material.

Conflicts of Interest: The authors declare no conflict of interest.

\section{Nomenclature}

$b \quad$ adsorption affinity, $\mathrm{kPa}^{-1}$

$b_{w} \quad$ van der Waals volume, $\mathrm{cm}^{3} / \mathrm{mol}$

c equilibrium uptake in volume ratio, $\mathrm{m}^{3} / \mathrm{kg}$ (or mol $/ \mathrm{kg}$ or $\mathrm{mmol} / \mathrm{g}$ )

$c_{0} \quad$ Volume-based maximum uptake, $\mathrm{m}^{3} / \mathrm{kg}$

$c_{p} \quad$ specific heat capacity, $\mathrm{J} / \mathrm{kg} \mathrm{K}$ (or J/g K)

COP coefficient of performance, -

$d_{p} \quad$ mean pore diameter, $\mathrm{nm}$

E characteristic energy, $\mathrm{J} / \mathrm{mol}$

$h \quad$ specific enthalpy, $\mathrm{kJ} / \mathrm{kg}$

K constant parameter for each adsorbent and adsorbate system, -

$q_{f g} \quad$ specific enthalpy of evaporation, $\mathrm{kJ} / \mathrm{kg}$

$m$ mass, $\mathrm{kg}$

$n \quad$ heterogeneity factor, -

$N_{A} \quad$ Avogadro constant, -

$P \quad$ pressure, $\mathrm{kPa}$

$P_{0} \quad$ saturation pressure, $\mathrm{kPa}$

$Q \quad$ specific heat, $\mathrm{kJ} / \mathrm{kg}$

$q \quad$ specific thermal energy, $\mathrm{kJ} / \mathrm{kg}$

$q_{s t} \quad$ isosteric heat of adsorption, $\mathrm{kJ} / \mathrm{kg}$

$R \quad$ gas constant, $\mathrm{J} / \mathrm{mol} \mathrm{K}$

SCP specific cooling power, $\mathrm{kJ} / \mathrm{kg}$

SHP specific heating power, $\mathrm{kJ} / \mathrm{kg}$

$T$ temperature, $\mathrm{K}$

$T_{b} \quad$ normal boiling temperature, $\mathrm{K}$

$V_{p} \quad$ pore volume, $\mathrm{cm}^{3} / \mathrm{g}$

$V_{M} \quad$ standard molar volume, $\mathrm{dm} 3 / \mathrm{mol}$

$v \quad$ specific volume, $\mathrm{m}^{3} / \mathrm{kg}$

$v_{b} \quad$ normal boiling point volume, $\mathrm{m}^{3} / \mathrm{kg}$

$w \quad$ equilibrium uptake in mass ratio, $\mathrm{kg} / \mathrm{kg}$

$w_{0} \quad$ mass-based maximum uptake, $\mathrm{kg} / \mathrm{kg}$ 


$\begin{array}{ll}\text { Subscripts } & \\ a & \text { adsorbed phase } \\ \text { ads } & \text { adsorbent (or adsorption) } \\ \text { Amb } & \text { ambient } \\ \text { cond } & \text { condensation } \\ \text { Crit } & \text { critical point } \\ \text { des } & \text { desorption } \\ \text { Eq } & \text { equilibrium } \\ \text { eva } & \text { evaporation } \\ f & \text { liquid phase } \\ g & \text { gaseous phase } \\ H & \text { high } \\ H X & \text { heat exchanger } \\ \text { Bed } & \text { bed of heat exchanger } \\ L & \text { low } \\ \text { Lat } & \text { latent } \\ \text { Sen } & \text { sensible } \\ S & \text { saturated } \\ M & \text { middle } \\ \text { max } & \text { maximum } \\ \text { min } & \text { minimum } \\ \text { Ph } & \text { pre-heating } \\ \text { Tot } & \text { total } \\ \text { Trip } & \text { triple } \\ \text { ref } & \text { refrigerant } \\ \text { Greek symbols } & \\ \alpha & \text { thermal expansion coefficient, } \mathrm{K}^{-1} \\ \varepsilon & \text { adsorption uptake, } \mathrm{JJ} / \mathrm{mol} \\ \rho & \text { density, g/cm } \\ & \end{array}$

\section{References}

1. Demir, H.; Mobedi, M.; Ülkü, S. A review on adsorption heat pump: Problems and solutions. Renew. Sustain. Energy Rev. 2008, 12, 2381-2403. [CrossRef]

2. Calm, J.M.; Didion, D.A. Trade-offs in refrigerant selections: Past, present, and future. Int. J. Refrig. 1998, 21, 308-321. [CrossRef]

3. Pal, A.; Uddin, K.; Thu, K.; Saha, B.B. Environmental assessment and characteristics of next generation refrigerants. Evergreen 2018, 5, 58-66. [CrossRef]

4. Sah, R.P.; Choudhury, B.; Das, R.K. A review on adsorption cooling systems with silica gel and carbon as adsorbents. Renew. Sustain. Energy Rev. 2015, 45, 123-134. [CrossRef]

5. El-Sharkawy, I.I.; Abdelmeguid, H.; Saha, B.B. Towards an optimal performance of adsorption chillers: Reallocation of adsorption/desorption cycle times. Int. J. Heat Mass Transf. 2013, 63, 171-182. [CrossRef]

6. Miyazaki, T.; Akisawa, A.; Saha, B.B.; El-Sharkawy, I.I.; Chakraborty, A. A new cycle time allocation for enhancing the performance of two-bed adsorption chillers. Int. J. Refrig. 2009, 32, 846-853. [CrossRef]

7. Aristov, Y.I.; Sapienza, A.; Ovoshchnikov, D.S.; Freni, A.; Restuccia, G. Reallocation of adsorption and desorption times for optimisation of cooling cycles. Int. J. Refrig. 2012, 35, 525-531. [CrossRef]

8. El-Sharkawy, I.I.; Pal, A.; Miyazaki, T.; Saha, B.B.; Koyama, S. A study on consolidated composite adsorbents for cooling application. Appl. Therm. Eng. 2016, 98, 1214-1220. [CrossRef]

9. Pal, A.; Shahrom, M.S.R.; Moniruzzaman, M.; Wilfred, C.D.; Mitra, S.; Thu, K.; Saha, B.B. Ionic liquid as a new binder for activated carbon based consolidated composite adsorbents. Chem. Eng. J. 2017, 326, 980-986. [CrossRef]

10. Pal, A.; El-Sharkawy, I.I.; Saha, B.B.; Jribi, S.; Miyazaki, T.; Koyama, S. Experimental investigation of $\mathrm{CO}_{2}$ adsorption onto a carbon based consolidated composite adsorbent for adsorption cooling application. Appl. Therm. Eng. 2016, 109, 304-311. [CrossRef]

11. Zheng, X.; Wang, L.W.; Wang, R.Z.; Ge, T.S.; Ishugah, T.F. Thermal conductivity, pore structure and adsorption performance of compact composite silica gel. Int. J. Heat Mass Transf. 2014, 68, 435-443. [CrossRef]

12. Wang, L.W.; Tamainot-Telto, Z.; Thorpe, R.; Critoph, R.E.; Metcalf, S.J.; Wang, R.Z. Study of thermal conductivity, permeability, and adsorption performance of consolidated composite activated carbon adsorbent for refrigeration. Renew. Energy 2011, 36, 2062-2066. [CrossRef]

13. Pal, A.; El-Sharkawy, I.I.; Saha, B.B.; Habib, K.; Miyazaki, T.; Koyama, S. Thermodynamic analysis of adsorption cooling cycle using consolidated composite adsorbents-Ethanol pairs. ARPN J. Eng. Appl. Sci. 2016, 11, 12234-12238. 
14. Pal, A.; Uddin, K.; Thu, K.; Saha, B.B. Activated carbon and graphene nanoplatelets based novel composite for performance enhancement of adsorption cooling cycle. Energy Convers. Manag. 2019, 180, 134-148. [CrossRef]

15. Berdenova, B.; Pal, A.; Muttakin, M.; Mitra, S.; Thu, K.; Saha, B.B.; Kaltayev, A. A comprehensive study to evaluate absolute uptake of carbon dioxide adsorption onto composite adsorbent. Int. J. Refrig. 2019, 100, 131-140. [CrossRef]

16. Rupa, M.J.; Pal, A.; Saha, B.B. Activated carbon-graphene nanoplatelets based green cooling system: Adsorption kinetics, heat of adsorption, and thermodynamic performance. Energy 2020, 193, 116774. [CrossRef]

17. Habib, K.; Saha, B.B.; Rahman, K.A.; Chakraborty, A.; Koyama, S.; Ng, K.C. Experimental study on adsorption kinetics of activated carbon/R134a and activated carbon/R507A pairs. Int. J. Refrig. 2010, 33, 706-713. [CrossRef]

18. Uddin, K.; Miyazaki, T.; Koyama, S.; Saha, B.B. Performance Investigation of Adsorption-Compression Hybrid Refrigeration Systems. Int. J. Air-Cond. Refrig. 2013, 21, 1350024. [CrossRef]

19. El-Sharkawy, I.I.; Uddin, K.; Miyazaki, T.; Saha, B.B.; Koyama, S.; Miyawaki, J.; Yoon, S.H. Adsorption of ethanol onto parent and surface treated activated carbon powders. Int. J. Heat Mass Transf. 2014, 73, 445-455. [CrossRef]

20. El-Sharkawy, I.I.; Saha, B.B.; Koyama, S.; He, J.; Ng, K.C.; Yap, C. Experimental investigation on activated carbon-ethanol pair for solar powered adsorption cooling applications. Int. J. Refrig. 2008, 31, 1407-1413. [CrossRef]

21. Azahar, F.H.M.; Mitra, S.; Yabushita, A.; Harata, A.; Saha, B.B.; Thu, K. Improved model for the isosteric heat of adsorption and impacts on the performance of heat pump cycles. Appl. Therm. Eng. 2018, 143, 688-700. [CrossRef]

22. Schüth, F.; Sing, K.S.W.; Weitkamp, J. Handbook of Porous Solids, 1st ed.; Wiley-VCH Verlag GmbH: Weinheim, Germany, 2002; ISBN 3-527-30246-8.

23. Rouquerol, F.; Rouquerol, J.; Sing, K.S.W.; Maurin, G. Introduction. In Adsorption by Powders and Porous Solids, 2nd ed.; Rouquerol, F., Rouquerol, J., Sing, K.S.W., Llewellyn, P., Maurin, G., Eds.; Principles, Methodology and Applications; Academic Press: Oxford, UK, 2014; pp. 1-24. [CrossRef]

24. Ülkü, S. Adsorption heat pumps. J. Heat Recover. Syst. 1986, 6, 277-284. [CrossRef]

25. Li, A.; Thu, K.; Ismail, A.B.; Shahzad, M.W.; Ng, K.C. Performance of adsorbent-embedded heat exchangers using binder-coating method. Int. J. Heat Mass Transf. 2016, 92, 149-157. [CrossRef]

26. Neveu, P.; Castaing, J. Solid-gas chemical heat pumps: Field of application and performance of the internal heat of reaction recovery process. Heat Recover. Syst. CHP 1993, 13, 233-251. [CrossRef]

27. Iloeje, O.C.; Ndili, A.N.; Enibe, S.O. Computer simulation of a CaCl2 solid-adsorption solar refrigerator. Energy 1995, $20,1141-1151$. [CrossRef]

28. Gluesenkamp, K.R.; Frazzica, A.; Velte, A.; Metcalf, S.; Yang, Z.; Rouhani, M.; Blackman, C.; Qu, M.; Laurenz, E.; Rivero-pacho, A.; et al. Experimentally Measured Thermal Masses of Adsorption Heat Exchangers. Energies 2020, 13, 1150. [CrossRef]

29. Loh, W.S. Experimental and Theoretical Studies of Waste Heat Driven Pressurized Adsorption Chillers; National University of Singapore: Singapore, 2010.

30. Thu, K.; Kim, Y.D.; Ismil, A.B.; Saha, B.B.; Ng, K.C. Adsorption characteristics of methane on Maxsorb III by gravimetric method. Appl. Therm. Eng. 2014, 72, 200-205. [CrossRef]

31. Mikšík, F.; Miyazaki, T.; Inada, M. Detailed investigation on properties of novel commercial mesoporous silica materials. Microporous Mesoporous Mater. 2019, 289, 109644. [CrossRef]

32. Lowell, S.; Shields, J.E.; Thomas, M.A.; Thommes, M. Thommes, Characterization of Porous Solids and Powders: Surface Area, Pore Size and Density; Particle Technology Series; Springer: Dordrecht, The Netherlands, 2004; Volume 16. [CrossRef]

33. Tarazona, P.; Marini Bettolo Marconi, U.; Evans, R.; Wills, H.H. Phase equilibria of fluid interfaces and conflned fluids non-local versus local density functionals. Mol. Phys. 1987, 60, 573-595. [CrossRef]

34. Tillner Roth, R.; Baehr, H.D. An International Standard Formulation for the Thermodynamic Properties of 1,1,1,2-Tetrafluoroethane (HFC-134a) for Temperatures from $170 \mathrm{~K}$ to $455 \mathrm{~K}$ and Pressures up to $70 \mathrm{MPa}$. J. Phys. Chem. Ref. Data 1994, 23, 657-729. [CrossRef]

35. Richter, M.; McLinden, M.O.; Lemmon, E.W. Thermodynamic properties of 2,3,3,3-tetrafluoroprop-1-ene (R1234yf): Vapor pressure and $\mathrm{p}-\rho-\mathrm{T}$ Measurements and an Equation of State. J. Chem. Eng. Data 2011, 56, 3254-3264. [CrossRef]

36. Thu, K.; Takezato, K.; Takata, N.; Miyazaki, T.; Higashi, Y. Performance Evaluation of a Heat Pump System using an HFC32/HFO1234yf Blend with GWP below 150 for Heating Applications. Appl. Therm. Eng. 2021, 182, 115952. [CrossRef]

37. Singh, V.K.; Kumar, E.A.; Saha, B.B. Adsorption isotherms, kinetics and thermodynamic simulation of CO2-CSAC pair for cooling application. Energy 2018, 160, 1158-1173. [CrossRef]

38. Chua, H.T.; Ng, K.C.; Chakraborty, A.; Oo, N.M.; Othman, M.A. Adsorption characteristics of silica gel + water systems. J. Chem. Eng. Data 2002, 47, 1177-1181. [CrossRef]

39. Ng, K.C.; Chua, H.T.; Chung, C.Y.; Loke, C.H.; Kashiwagi, T.; Akisawa, A.; Saha, B.B. Experimental investigation of the silica gel-water adsorption isotherm characteristics. Appl. Therm. Eng. 2001, 21, 1631-1642. [CrossRef]

40. Hatch, C.D.; Wiese, J.S.; Crane, C.C.; Harris, K.J.; Kloss, H.G.; Baltrusaitis, J. Water Adsorption on Clay Minerals As a Function of Relative Humidity: Application of BET and Freundlich Adsorption Models. Langmuir 2012, 28, 1790-1803. [CrossRef] [PubMed]

41. Saha, B.B.; Uddin, K.; Pal, A.; Thu, K. Emerging sorption pairs for heat pump applications: An overview. JMST Adv. 2019, 1, 161-180. [CrossRef]

42. Zhu, W.; Groen, J.C.; Van Miltenburg, A.; Kapteijn, F.; Moulijn, J.A. Kureha activated carbon characterized by the adsorption of light hydrocarbons. Stud. Surf. Sci. Catal. 2006, 160, 287-294. 
43. Dada, A.O.; Olalekan, A.P.; Olatunya, A.M.; Dada, O. Langmuir, Freundlich, Temkin and Dubinin-Radushkevich Isotherms Studies of K. IOSR J. Appl. Chem. 2012, 3, 38-45. [CrossRef]

44. Bering, B.P.; Gordeeva, V.A.; Dubinin, M.M.; Efimova, L.I.; Serpinskii, V.V. Development of concepts of the volume filling of micropores in the adsorption of gases and vapors by microporous adsorbents-Communication 4 . Differential heats and entropies of adsorption. Bull. Acad. Sci. USSR Div. Chem. Sci. 1971, 20, 17-22. [CrossRef]

45. Wood, G.O. Affinity coefficients of the Polanyi/Dubinin adsorption isotherm equations. Carbon N. Y. 2001, 39, 343-356. [CrossRef]

46. Ozawa, S.; Kusumi, S.; Ogino, Y. Physical adsorption of gases at high pressure. IV. An improvement of the Dubinin-Astakhov adsorption equation. J. Colloid Interface Sci. 1976, 56, 83-91. [CrossRef]

47. Dubinin, M.M. Physical Adsorption of Gases and Vapors in Micropores. Prog. Surf. Membr. Sci. 1975, 9, 1-70. [CrossRef]

48. Chakraborty, A.; Saha, B.B.; Koyama, S.; Ng, K.C. On the thermodynamic modeling of the isosteric heat of adsorption and comparison with experiments. Appl. Phys. Lett. 2006, 89, 171901. [CrossRef]

49. Chakraborty, A.; Saha, B.B.; El-Sharkawy, I.I.; Koyama, S.; Srinivasan, K.; Ng, K.C. Theory and experimental validation on isosteric heat of adsorption for an adsorbent + adsorbate system. High Temp. High Press. 2008, 37, 109-117.

50. Chakraborty, A.; Saha, B.B.; Ng, K.C.; Koyama, S.; Srinivasan, K. Theoretical insight of physical adsorption for a single component adsorbent + adsorbate system: II. The Henry region. Langmuir 2009, 25, 7359-7367. [CrossRef]

51. Aristov, Y. Concept of adsorbent optimal for adsorptive cooling/heating. Appl. Therm. Eng. 2014, 72, 166-175. [CrossRef]

52. Pinheiro, J.M.; Salústio, S.; Rocha, J.; Valente, A.A.; Silva, C.M. Adsorption heat pumps for heating applications. Renew. Sustain. Energy Rev. 2020, 119. [CrossRef]

53. Cacciola, G.; Restuccia, G. Reversible adsorption heat pump: A thermodynamic model. Int. J. Refrig. 1995, 18, 100-106. [CrossRef]

54. Uddin, K.; Amirul Islam, M.; Mitra, S.; Lee, J.B.; Thu, K.; Saha, B.B.; Koyama, S. Specific heat capacities of carbon-based adsorbents for adsorption heat pump application. Appl. Therm. Eng. 2018, 129, 117-126. [CrossRef]

55. Solberg, S.Ø.; Yndgaard, F. Trait Patterns and Genetic Resources of Dill (Anethum graveolens L.). ASM Handb. 2018, 15, 468-481. [CrossRef]

56. Seo, S.; Kawakami, H.; Miksik, F.; Takata, N.; Thu, K.; Miyazaki, T. Thermodynamic analysis and impact of thermal masses on adsorption cycles using MaxsorbIII/R245fa and SAC-2/R245fa pairs. Int. J. Refrig. 2021, 123, 52-62. [CrossRef]

57. Askalany, A.A.; Saha, B.B. Experimental and theoretical study of adsorption kinetics of Difluoromethane onto activated carbons. Int. J. Refrig. 2015, 49, 160-168. [CrossRef]

58. Wang, J.; Guo, X. Adsorption isotherm models: Classification, physical meaning, application and solving method. Chemosphere 2020, 258, 127279. [CrossRef] [PubMed]

59. Askalany, A.A.; Saha, B.B.; Uddin, K.; Miyzaki, T.; Koyama, S.; Srinivasan, K.; Ismail, I.M. Adsorption isotherms and heat of adsorption of difluoromethane on activated carbons. J. Chem. Eng. Data 2013, 58, 2828-2834. [CrossRef] 